\title{
Consenso Fiscal. Una mirada desde la teoría de los juegos
}

Fiscal Consensus. A look at it from game theory

Consenso Fiscal. Uma olbada desde a teoria dos jogos

Consensus fiscal. Un regard sur la théorie des jeux 税收共识。博恋论的视角。

Luciano Vernetti ${ }^{1}$

Universidad de Buenos Aires - Argentina

Revista Derechos en Acción ISSN 2525-1678/ e-ISSN 2525-1686

Año 5/No 14 VERANO 2019/20 (21 diciembre a 20 marzo), 400-451

DOI: https://doi.org/10.24215/25251678e364

ORCID: https://orcid.org/0000-0002-5370-8438

Recibido: 01/11/2019

Aprobado: 09/02/2020

Resumen: La aplicación de la teoría de los juegos, en especial de "La batalla de los sexos" facilita el análisis del proceso de negociación y los motivos por los que se producen los resultados. Se ha podido verificar que los actores se integran formando constelaciones, en las cuales, dependiendo de las circunstancias históricas, el factor común de unión puede variar. En algunos casos la unión es de tipo político, en otros la unión es por características de las provincias (chicas o grandes), actividades económicas relevantes en las provincias (por ej. el petróleo o la actividad vitivinícola), y en otras la unión está basada en la resistencia a la propuesta.

Palabras clave: Derecho Fiscal; teoría de los juegos

Abstract: The application of game theory, especially "The Battle of the Sexes" facilitates the analysis of the negotiation process and the reasons

1 Abogado, especialista en Tributación por la Universidad de Buenos Aires, Argentina. 
for the results. It has been possible to verify that the actors are integrated forming constellations, in which, depending on the historical circumstances, the common factor of union can vary. In some cases the union is political, in others the union is due to characteristics of the provinces (small or large), relevant economic activities in the provinces (e.g. oil or wine activity), and in others the union is based on resistance to the proposal.

Keywords: Tax law; game theory

Resumo: A aplicação da teoria dos jogos, especialmente "A Batalha dos Sexos" facilita a análise do processo de negociação e as razões pelas quais os resultados são produzidos. Verificou-se que os atores se integram formando constelações, nas quais, dependendo das circunstâncias históricas, o fator comum de união pode variar. Em alguns casos a união é de tipo político. em outros a união é por características das províncias (pequenas ou grandes), atividades econômicas relevantes nas províncias (por exemplo petróleo ou a atividade de vinificação), e em outros a união baseia-se na resistência à proposta.

Palavras-chave: Direito Fiscal; teoria dos jogos

Résumé: L'application de la théorie des jeux, en particulier "La Bataille des Sexes" facilite l'analyse du processus de négociation et les raisons pour lesquelles les résultats sont produits. II a été vérifié que les acteurs s'intègrent en formant des constellations dans lesquelles, selon les circonstances historiques, le facteur commun d'union peut varier. Dans certains cas, I'union est politique, dans d'autres, elle est basée sur les caractéristiques des provinces (petites ou grandes), les activités économiques de chacune (par exemple, activité pétrolière ou viticole), et dans d'autres, l'union est fondée sur la résistance à la proposition.

Mots clés: droit fiscal; théorie des jeux

摘要：博弯论的应用, 尤其是 “性别之战”, 有助于分析谈判过程以及 产生结果的原因。业已证实, 行为者整合了形成的星座, 在其中, 根 据历史情况, 结合的共同因素会有所不同。在某些情况下, 工会是政 治性的, 而在另一些情况下, 工会是由于各省 (大小)的特征, 各省的 相关经济活动 (例如, 石油或葡萄酒活动)引起的, 而在其他情况下, 工会则是由于基于对该建议的反对。

关键词：税法博弯论 


\section{Introducción}

En el año 2017 en la República Argentina al firmarse el pacto entre la Nación y las provincias denominado "Consenso Fiscal", se produjo un proceso similar o asimilable al "Pacto Federal Fiscal I" y lo sucedido al tiempo de firmarse el mismo en el año 1992.

Con relación al "Pacto Federal Fiscal I" Cristian Altavilla ha realizado un interesante trabajo titulado "Procesos de Negociación en las relaciones intergubernamentales" en el cual se aborda el análisis de las relaciones y negociaciones intergubernamentales desde la teoría de los juegos. La ciencia jurídica, como ciencia social, debe -entre otras cosas- entender, comprender y explicar la forma en que se modifica el derecho vigente, y cómo son los procesos sociales y socio jurídicos que traen cambios en el ordenamiento vigente.

Altavilla aborda dicha tarea desde el ámbito de la teoría de los juegos, esbozando una hipótesis con relación a cómo se arribó al Pacto Federal Fiscal I, esta hipótesis pudo ser verificada en forma positiva. La pretensión del presente trabajo es intentar verificar si la hipótesis postulada puede ser verificada con relación al "Consenso Fiscal", o si cuando la aplicamos en este caso la hipótesis es refutada.

La ciencia no sólo avanza con la formulación de nuevas tesis e hipótesis sino también con poner a prueba todas las veces que se pueda una existente.

\section{Procesos de Negociación en las relaciones intergubernamentales. Ayer y hoy el mismo problema}

Altavilla realiza un análisis de la situación fiscal acaecida durante la década de 1990, con especial referencia a los pactos

\footnotetext{
2 Altavilla, Cristian (2012). "Procesos de Negociación en las relaciones intergubernamentales. El Pacto Fiscal Federal I", Revista Perspectivas de Políticas Públicas, Argentina, Año 1 № 2 (Enero-junio 2012), pp. 175-220.
} 
suscriptos en dicho contexto vinculados a la distribución de recursos coparticipables y la distribución del poder tributario, explicando:

"Todos estos acuerdos fueron llevados a cabo a través de acuerdos formales (que recibieron el nombre de pactos fiscales) celebrados entre los titulares de los poderes ejecutivos tanto de la nación como de cada una de las provincias que integran la federación argentina. Esto implicó el consentimiento previo prestado por los gobernadores que -de esta manera- vienen a consentir el proceso de reforma llevado adelante por el gobierno nacional. A pesar de ello, los gobernadores (principales actores intervinientes en estos procesos de negociación) no quedaron del todo satisfechos con los resultados obtenidos y puede observarse que en el largo plazo tales acuerdos fueron en detrimento de las provincias. ¿Por qué entonces estos pactos fueron firmados por los gobernadores?"3

Desde el inicio de la gestión del ex presidente Macri en el gobierno nacional, se planteó como objetivo la firma de nuevos acuerdos fiscales que permitan culminar con una nueva Ley de Coparticipación Federal.

Ya en un comienzo la postura, de esa gestión, del gobierno nacional fue tomar la iniciativa, a poco de asumir dictó el Decreto de Necesidad y Urgencia $N^{\circ} 73 / 2016^{4}$ derogando el Decreto de Necesidad y Urgencia $N^{\circ} 2.635 / 2015^{5}$ que había dispuesto el cese para todas las provincias de la detracción del quince por ciento de la masa de impuestos coparticipables destinado al sistema previsional, generalizando los efectos de las resoluciones de la Corte Suprema de Justicia de la Nación dictadas en juicios iniciados por algunas provincias. De esta forma, y con los fondos en

\footnotetext{
3 Altavilla, Cristian (2012). "Procesos ...", ob . cit., p. 176.

4 Poder Ejecutivo Nacional. Decreto 73/2016, recuperado el 14 de diciembre de 2017 de http://servicios.infoleg.gob.ar/infoleglnternet/anexos/255000-259999/257722/norma.htm.

5 Poder Ejecutivo Nacional. Decreto 2635/2015, recuperado el 14 de diciembre de 2017 de http://servicios.infoleg.gob.ar/infoleglnternet/anexos/255000-259999/255838/norma.htm.
} 
sus arcas nuevamente en su poder la Nación inició un proceso de negociación culminando ello en el "Acuerdo de devolución del 15 \%" suscrito el 23 de mayo de 2016. Más cerca en el tiempo se firma en agosto de 2017 el pacto de responsabilidad fiscal ${ }^{6}$ y el 16 de noviembre de 2017 el "Consenso Fiscal".

Como puede verse los procesos de 1990 - 1993 son similares -no iguales- a los ocurridos entre 2015 y 2017, en especial lo ocurrido entre el "Pacto Federal Fiscal I" y el "Consenso Fiscal", siendo válida para este último la pregunta ¿Por qué firmaron los gobernadores?

Para dar respuesta a dicha pregunta con relación al "Pacto Federal Fiscal I" Altavilla propuso el siguiente esquema:

"(es) necesario poner de resalto qué variables han intervenido en aquellos procesos de negociación, como así también identificar con qué recursos cuentan cada uno de los actores intervinientes y cómo han sido utilizados, qué percepciones han tenido estos actores sobre el contexto, sobre los demás actores y sobre todo, cómo han percibido las potenciales pérdidas y ganancias puestas en juego. Finalmente, cuál es el marco institucional dentro del cual aquellas relaciones fueron llevadas a cabo y cómo estas reglas influyeron sobre los actores, sus recursos y sus decisiones."

La hipótesis de trabajo se basa en que:

"ciertas características del diseño institucional posibilitan comportamientos oportunistas y de "free rider" en ambos niveles de gobierno. El contexto institucional donde los actores se desenvuelven está definido por su debilidad (dado que no constriñe lo suficientemente los comportamientos oportunistas) y, consecuentemente,

6 Jueguen, Francisco (18/08/2017). “El Gobierno pacta con los gobernadores contener el gasto y el empleo público". La Nación, recuperado el 16 de diciembre de 2017 de https:// www.lanacion.com.ar/2054405-el-gobierno-pacta-con-los-gobernadores-contener-el-gastoy-el-empleo-publico.

7 Altavilla, Cristian (2012). "Procesos ...", ob . cit., p. 176. 
por su maleabilidad y flexibilidad por parte de los mismos actores involucrados en orden a sus propios intereses. En consecuencia, el comportamiento oportunista y de corto plazo es parte del conjunto de reglas que rigen las relaciones entre los distintos niveles de gobierno"

Como primera aprensión nos surge la ausencia del concepto de "free rider", fin de superar ello entenderemos el concepto en el marco de la teoría de los juegos como aquel sujeto que trata de maximizar su beneficio a costa de los demás e incluso a costa de lo que podríamos denominar el bien común, o en otras palabras aquel individuo que se beneficia mientras otros asumen los costos o esfuerzos, convirtiéndose en la principal dificultad para que se provean voluntariamente bienes públicos.

\section{Marco teórico. Institucionalismo de actores.}

Exponiendo el marco teórico Altavilla explica:

"El supuesto principal de nuestro marco teórico parte del impacto que tienen las instituciones sobre el sistema político y, en particular, sobre los actores que en él se desenvuelven. En el primer caso (es decir, el impacto sobre el sistema político), el marco institucional delimitará sus capacidades de resolución de conflictos y la efectividad de las mismas; en el segundo caso (el impacto sobre los actores políticos), las instituciones actuarán como factores que imponen restricciones al libre actuar de los individuos, al mismo tiempo que moldean las preferencias y percepciones de estos; asimismo, las instituciones forman y moldean las capacidades con que han de actuar aquellos y les da el alcance que efectivamente puedan llegar a tener. Una herramienta analítica que

\footnotetext{
8 Altavilla, Cristian (2012). “Procesos ...", ob . cit., p. 177.

9 La traducción literal del este anglicismo es jinete libre o conductor libre, y la definición del diccionario de inglés para dicha frase significa una persona o empresa que obtiene una ventaja sin pagarla ni ganarla. Véase https://dictionary.cambridge.org/es/diccionario/ingles/ free-rider.
} 
resulta propicia para encarar el análisis desde lo institucional es el denominado institucionalismo centrado en actores (actor-centered institutionalism). Este nuevo enfoque realiza una especial combinación de los conceptos constelaciones de actores y de modos de interacción. Una constelación es el conjunto de actores (con sus respectivas capacidades y orientaciones de acción - percepciones y preferencias) involucrados en un determinado proceso político, y el posible resultado de una política como consecuencia de las decisiones estratégicas empleadas por aquellos. El concepto se asemeja a la noción de "matriz de juego" que emplea la teoría de juegos tradicional, pero introduce una modificación que resulta sustancial. Mientras el "juego", desde el enfoque de la teoría de juegos, es descripto a partir del supuesto de que los jugadores están usualmente asociados con un único modo de interacción entre ellos (generalmente en el modo de un juego no cooperativo): "nuestra conceptualización asume que en principio cada constelación dada puede ser jugada en una variedad de modos de interacción - no sólo como un juego "no cooperativo", sino también como un «juego cooperativo" (cuando las estrategias son elegidas por un acuerdo negociado) o como un "juego de voto" (cuando las estrategias están determinadas por la regla de la mayoría) o como un "juego jerárquico" (cuando las estrategias de uno o más actores pueden ser determinadas por la elección unilateral de otro actor)" (Scharpf 1997:69)."10

\section{Finalmente agrega}

"Constelaciones de actores. Conservando el poder analítico de la teoría de los juegos, pero sin caer en el error de observar al mundo en términos de juegos no cooperativos, Scharpf (1997) utiliza la idea de matriz de juego, a la que denominará constelación de actores: "Las "constelaciones de actores" se supone que representan lo que sabemos del conjunto de actores que están involucrados realmente en interacciones políticas particulares - sus capacidades

10 Altavilla, Cristian (2012). "Procesos ...", ob . cit., p. 177. 
(traducidas en potenciales "estrategias»), sus percepciones y evaluaciones de los resultados obtenibles (traducidos en "pagos") y el grado en que sus aspiraciones de pagos son compatibles o incompatibles entre sí" (Scharpf 1997:72)."11

En las relaciones entre el actor y las instituciones, la incidencia de estas se da por el lado de las percepciones, las preferencias y las capacidades de los actores individuales o colectivos, y en la forma en que estos actúan.

Las instituciones son, sin duda, la principal fuente de información de los actores y el principal factor que influye sobre sus decisiones, en el sentido de que reducen los incentivos para seguir ciertas estrategias de acción y aumentan los incentivos para realizar otras ${ }^{12}$. Las instituciones varían entre sociedades de diferentes naciones y también cambian a lo largo del tiempo.

En cuanto al aspecto decisional Zurbriggen explica:

“...las instituciones no influyen en las decisiones de una manera determinista, puesto que siempre existen distintas posibilidades de acción que dejan un amplio margen para que los actores elijan entre diferentes opciones tácticas y estratégicas (Scharpf, 1997: 39-42) ...Ello implica reconocer que los resultados de política no son un simple cumplimiento de reglas institucionalizadas o normas culturales, sino que es una acción que el actor desarrolla con una intencionalidad: la de obtener resultados preconcebidos." ${ }^{13}$

\section{Contexto. Actores e Instituciones}

En este punto se intenta exponer el contexto en el que fue desarrollado el proceso de negociación del "Consenso Fiscal",

\footnotetext{
11 Altavilla, Cristian (2012). "Procesos ..., ob . cit., p. 178.

12 Zurbriggen, Cristina (2006). "El institucionalismo centrado en los actores: una perspectiva analítica en el estudio de las políticas públicas". Revista de Ciencia Política, Santiago de Chile, Volumen 26, No 1 (2006), pp. 67-83, recuperado el 18 de enero de 2018 de https://dx.doi. org/10.4067/S0718-090X2006000100004.

13 Zurbriggen, Cristina (2006). "El institucionalismo...", ob. cit.
} 
los actores que intervinieron y las instituciones que regulaban la actuación de estos.

\section{IV.1. Contexto}

En cuanto al contexto en que se desarrolló la negociación para arribar al acuerdo existen algunos hechos que son importantes a los efectos del análisis. Hoy estamos temporalmente cerca de los hechos, ello tiene como ventaja haber podido seguir momento a momento lo acontecido, por otro lado tiene como desventaja no tener una perspectiva histórica sobre los efectos concretos del "Consenso Fiscal".

\section{IV.1.1. Elecciones 2017}

El 22 de octubre de 2017 se celebraron las elecciones legislativas de medio término, que renovaron la mitad de la Cámara de Diputados de la Nación y un tercio del Senado de la Nación, como resultado de dicha elección la alianza política "Cambiemos"14 que lideraba el ex presidente Macri se impuso en trece provincias y consolidó su triunfo como la fuerza más votada a nivel país.

El Dr. Federico Landera en el informe publicado para la Universidad Austral ${ }^{15}$, señala que Cambiemos obtuvo el primer lugar en las elecciones legislativas para diputados nacionales con el $41,76 \%$, logrando un crecimiento del $21,64 \%$ con respecto a las elecciones presidenciales del 2015. Con el 21,83\%,

\footnotetext{
14 El término "Cambiemos" será utilizado para denominar a la alianza de gobierno que en encabeza el presidente Marcri. Entre las principales fuerzas que forman la alianza son la Unión Cívica Radical y la Coalición Cívica.

15 Landera, Federico (2017). "Elecciones 2017 vs. 2015: el nuevo mapa político del país". Universidad Austral. Se ha consultado una presentación recuperada el 10 de enero de 2018 de https://www.slideshare.net/ jucarguello/elecciones-2017-vs-2015-el-nuevo-mapapoltico-del-pas?from_action=save. Véase también presentación oficial de la Universidad en http://www.austral.edu.ar/contenido/2017/10/elecciones-2017-vs-2015-el-nuevo-mapapolitico-del-pais/
} 
el "Kirchnerismo"16 obtuvo el segundo lugar en las elecciones del 2017 y sufrió un retroceso del $40,77 \%$ con respecto a las elecciones del 2015.

El citado informe da cuenta de las importantes modificaciones a nivel político que ocurrió en las provincias. Cambiemos fue la fuerza política que ganó en más provincias (trece) y el kirchnerismo sólo en tres. En las elecciones del 2015 Cambiemos había ganado en cuatro provincias y el Kirchnerismo en diecisiete. La infografía ${ }^{17}$ refleja en forma visual las modificaciones políticas producidas por las elecciones.

\section{5}

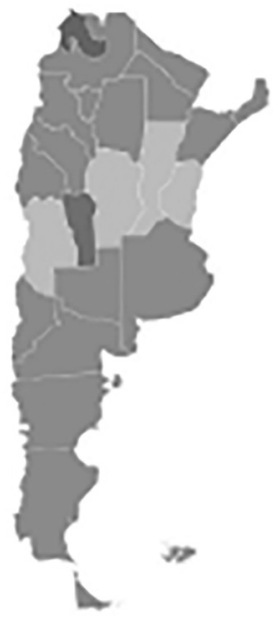

\section{7}

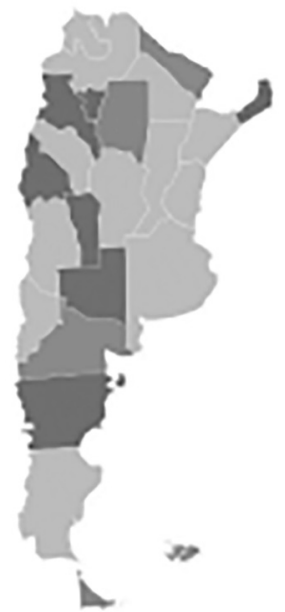

Gris medio: Kirchnerismo y aliados. Jujuy izq.: Massismo.

Gris oscuro y Santiago del Estero der.: Partidos Justicialista y partidos provinciales. Gris claro: Cambiemos.

16 El término "Kirchnerismo" será utilizado para denominar a la fuerza política que encabeza la ex presidenta Fernandez de Krirchner. Esta alianza está compuesta por distintos partidos y agrupaciones que se han presentado anteriormente bajo la denominación "Frente para la victoria" y en las elecciones 2017 bajo la denominación "Unidad Ciudadana".

17 Landera, Federico (2017). "Elecciones...", ob. cit. 
Ello trajo como consecuencia que la Cámara de Diputados se modificara de la siguiente forma:

\begin{tabular}{|l|c|c|c|c|c|}
\hline \multicolumn{1}{|c|}{ Partido o Alianza } & $\mathbf{2 0 1 5}$ & $\begin{array}{c}\text { \% Dipu- } \\
\text { tados }\end{array}$ & $\mathbf{2 0 1 7}$ & $\begin{array}{c}\text { \% Dipu- } \\
\text { tados }\end{array}$ & \% Variación \\
\hline Cambiemos & 86 & $33,46 \%$ & 107 & $41,63 \%$ & $24,42 \%$ \\
\hline $\begin{array}{l}\text { Unidad Ciudadana y } \\
\text { aliados (Kirchnerismo) }\end{array}$ & 75 & $29,18 \%$ & 67 & $26,07 \%$ & $-10,67 \%$ \\
\hline Partido Justicialista & 38 & $14,79 \%$ & 40 & $15,56 \%$ & $5,26 \%$ \\
\hline $\begin{array}{l}\text { Frente Renovador y } \\
\text { Aliados (Massismo) }\end{array}$ & 35 & $13,62 \%$ & 21 & $8,17 \%$ & $-40,00 \%$ \\
\hline Izquierda & 4 & $1,56 \%$ & 3 & $1,17 \%$ & $-25,00 \%$ \\
\hline Otros & 19 & $7,39 \%$ & 19 & $7,39 \%$ & $0,00 \%$ \\
\hline Totales & 257 & $100,00 \%$ & 257 & $100,00 \%$ & \\
\hline
\end{tabular}

Por su parte el senado se modificó de esta manera:

\begin{tabular}{|l|c|c|c|c|c|}
\hline \multicolumn{1}{|c|}{ Partido o Alianza } & $\mathbf{2 0 1 5}$ & \% Senado & $\mathbf{2 0 1 7}$ & \% Senado & $\begin{array}{c}\% \\
\text { Variación }\end{array}$ \\
\hline Cambiemos & 15 & $20,83 \%$ & 24 & $33,33 \%$ & $60,00 \%$ \\
\hline $\begin{array}{l}\text { Unidad Ciudadana y } \\
\text { aliados (Kirchnerismo) }\end{array}$ & 18 & $25,00 \%$ & 10 & $13,89 \%$ & $-44,44 \%$ \\
\hline Partido Justicialista & 25 & $34,72 \%$ & 23 & $31,94 \%$ & $-8,00 \%$ \\
\hline Otros & 14 & $19,44 \%$ & 15 & $20,83 \%$ & $7,14 \%$ \\
\hline Totales & 72 & $100,00 \%$ & 72 & $100,00 \%$ & \\
\hline
\end{tabular}

\section{IV.1.2. Cronología de un proceso}

Concluidas las elecciones, el gobierno nacional se encuentra con el poder político consolidado, y el 30 de octubre de $2017^{18}$ el ex presidente decide plantear los nuevos ejes de Gobierno en el Centro Cultural Kirchner dándole cita a los gobernadores de las provincias. De acuerdo con la prensa, "El Presidente convocó

18 Difusionlnfo (30/10/2017). "Histórico discurso del Presidente Macri en el CCK / 30-10-2017" [video]. Consultado el 17 de diciembre de 2017 de https://youtu.be/Eb6H3i6_2i0. 
a un amplio acuerdo nacional para crear empleo y reducir la pobreza"19, y entre las palabras de éste se citaba:

"Los convoco a lograr entre todos consensos básicos [...] Tenemos que avanzar en reformas donde cada uno ceda un poco, empezando por los que tienen poder. Y no solo hablo de la política [...] Tenemos que hacerlo en base de la confianza, hablando con la verdad, la buena fe, sin doble discurso, dejando de lado las etiquetas y discursos que impidan que ese diálogo fluya. No digo que sea fácil. El cambio cuesta, pero no hay excusas para no animarse. No hay más excusas. Es ahora o nunca" ${ }^{20}$.

Entre los ejes del discurso se planteó la "Responsabilidad fiscal"21. Macri llamó a bajar el gasto público y controlar las cuentas provinciales y anunció que presentará un proyecto de reforma tributaria. El ex presidente señaló que era necesaria una nueva relación fiscal entre la Nación y las provincias, con una distribución de recursos "equitativa" agregando que otro tema a trabajar es "desandar juntos la escalada de impuestos", "necesitamos menos impuestos... y todo esto lo debemos lograr con equilibrio fiscal". Puntualmente luego señaló "Lamentablemente tenemos impuestos que ningún país tiene, impuestos demasiado altos, con una distribución poco equitativa y un sistema impositivo complicado y engorroso"22, "... por eso queremos avanzar con las provincias y con los municipios ... el miércoles vamos a presentar un esquema de reforma tributaria con mira en la equidad y el largo plazo..."23.

19 La Nación (30/10/2018). "Mauricio Macri, en el CCK: "Tenemos que avanzar en reformas donde cada uno ceda un poco", recuperado el 16 de diciembre de 2017 de http://www.lanacion.com.ar/2077597-mauricio-macri-plan-de-reformas-cck.

20 La Nación (30/10/2017). "Mauricio..., ob. cit.

21 Difusionlnfo (30/10/2017). "Histórico ...", ob. cit. Véase el momento preciso del discurso en https://youtu.be/Eb6H3i6_2i0?t=689.

22 Difusionlnfo (30/10/2017). "Histórico ...", ob. cit. Véase el momento preciso del discurso en https://youtu.be/Eb6H3i6_2i0?t=1009.

23 Difusionlnfo (30/10/2017). "Histórico ...", ob. cit. Véase el momento preciso del discurso en https://youtu.be/Eb6H3i6_2iO?t=1009. 
Así el gobierno nacional es quien realiza la primera movida. En la semana que principió el 6 de noviembre de 2017 existieron muchas reuniones bilaterales con gobernadores y ministros de provincias $^{24}$.

La primera movida del gobierno se completa con la reunión del 9 de noviembre, en la cual el ex presidente junto a sus principales ministros presenta a los gobernadores el modelo de pacto denominado "Consenso Fiscal" con la clara idea de firmarlo el 12 de noviembre de 2017.

La reacción de los gobernadores, de acuerdo con la prensa fue la siguiente:

"Casi uniforme, el mutismo -o la opinión superficial- de los gobernadores fue la respuesta más elocuente al "consenso fiscal" que les propuso Mauricio Macri, un pacto en los papeles gradual para eliminar Ingresos Brutos y sellar el déficit cero... El texto tensó a los gobernadores que, rápido, pusieron a sus gabinetes a analizar el impacto en sus provincias. No sólo por la baja, progresiva hasta 2021, de IIBB $^{25}$ a la actividad productiva sino por un manojo de medidas sensibles..."26

Como elementos de presión surgieron:

“...por un lado, que en los distritos que no adhieran empezará a regir el Pacto Fiscal de 1993 que impone una baja brusca de II.BB., a la vez que dejarán de recibir recursos del Fondo Sojero..." ${ }^{27}$

\footnotetext{
24 Mercado, Silvia (09/11/2017). "Todo listo para la firma de los primeros acuerdos entre Mauricio Macri y los gobernadores". Infobae, recuperado el 17 de diciembre de 2017 de https://www.infobae.com/ politica/2017/11/09/todo-listo-para-la-firma-de-los-primerosacuerdos-entre-mauricio-macri-y-los-gobernadores/

25 La forma común de abreviar el tributo local denominado "Impuesto sobre los Ingresos Brutos" es IIBB o II.BB.

26 Ibáñez, Pablo (09/11/2017). "Los detalles del Pacto Fiscal que el Gobierno negocia con las provincias". Clarín, recuperado el 17 de diciembre de 2017 de https://www.clarin.com/ politica/inquietud-provincias-preparan-discutir-letra-chica_0_BkXI1rMkf.html.

27 Ibáñez, Pablo (09/11/2017). "Los detalles...", ob. cit.
} 
y como elemento de concesión:

“...La promesa de Macri, volcada al papel, es compensar a las provincias con un Fondo que en 2018 será de 16 mil millones y darle recursos extra a la gestión de María Eugenia Vidal...”

“...Como zanahoria, está la resolución del conflicto por el Fondo del Conurbano, que no implicaría drenar los recursos de las otras provincias..." 28 .

Al día siguiente comenzó otra nueva ronda de reuniones bilaterales, ello era así reflejado:

“...El Gobierno apuesta a cerrar el acuerdo por el Pacto Fiscal el próximo jueves para lo cual desde hoy iniciarán una ronda de negociaciones individuales con los mandatarios provinciales..." 29

Luego de la presentación e impulso inicial, las voces comenzaron a alzarse en contra de un cierre rápido:

“...a contramano del apuro de Mauricio Macri, los gobernadores opositores ven difícil la posibilidad de firmar el jueves próximo el pacto fiscal que el Gobierno les presentó la semana pasada. Los motivos del escepticismo son varios. El principal, coinciden los caciques del PJ, es la heterogeneidad de situaciones, prioridades y urgencias de las provincias de cara a la reforma. "Veo muy difícil que lleguemos al jueves. Son demasiadas cosas muy complejas y muy poco tiempo', sintetizó un ministro de Finanzas del Norte. 'Además del tiempo, dependemos del grado de flexibilidad que muestre el Gobierno

28 Pertot, Werner (13/11/2017). "Zanahoria y garrote para las provincias". Página 12, recuperado el 16 de diciembre de 2017 de https://www.pagina12.com.ar/75591-zanahoriay-garrote-para-las-provincias.

29 Torino, Martín (10/11/2017). "El Gobierno prevé cerrar el acuerdo el próximo jueves, pero con disensos". El Cronista, recuperado el 16 de diciembre de 2017 de https://www.cronista. com/economiapolitica/El-Gobierno-preve-cerrar-el-acuerdo-el-proximo-jueves-pero-con-disensos-20171110-0056.html. 
para hacer correcciones', aportó el vocero de otro gobernador peronista..." 30

En forma individual las provincias llevaron distintos reclamos y objeciones:

“... 'Está durísimo, algunos piden todo', advertía con fastidio ayer al caer la tarde uno de los funcionarios que recibió ministros de Economía provinciales en la previa de la nueva convocatoria de Mauricio Macri a los gobernadores este jueves, en la Casa Rosada. El Gobierno busca conseguir la firma de buena parte de los mandatarios para avanzar con un amplio paquete de reformas en el Congreso, aunque ante el escenario complicado ya evalúa alternativas, como avanzar con un acuerdo marco y seguir la discusión en el ámbito legislativo" ${ }^{1}$

La estrategia de las reuniones bilaterales se reflejaba de esta manera:

"Para el Gobierno las llamadas 'bilaterales' tienen como objetivo por un lado cotejar y revisar los números de las reformas fiscales, tributarias y previsionales anunciadas por Macri. Y más allá de la discusión técnica, evitar que a partir de los reclamos los mandatarios peronistas unifiquen posiciones para bloquear los proyectos en el Congreso. "Que no se cierren ni se abroquelen", se propusieron en la Casa Rosada"32.

Como elementos facilitadores y de presión surgían:

"Como muestra de buena voluntad, en la Casa Rosada adelantaron que la reducción en Ingresos Brutos podrá

\footnotetext{
30 Bullrich, Lucrecia (12/11/2017). "Los gobernadores dudan de que se pueda firmar el pacto fiscal esta semana". La Nación, recuperado el 16 de diciembre de 2017 de http://www. lanacion.com.ar/2081633-los-gobernadores-dudan-de-que-se-pueda-firmar-el-pacto-fiscalesta-semana.

31 Bravo, Martín (14/11/2017). "Pacto fiscal: el Gobierno le mete presión a las provincias, pero ya analiza alternativas para el acuerdo". Clarín, recuperado el 16 de diciembre de 2017 de https://www.clarin.com/politica/gobierno-presiona-evalua-alternativas_0_H11ap1YJf.html 32 Bravo, Martín (14/11/2017). "Pacto...", ob. cit.
} 
tener diferentes niveles de acuerdo a las dificultades de cada provincia, uno de los pedidos de los mandatarios. 'No les vamos a decir cuánto a cada uno, lo importante es que haya una tendencia a la baja', aseguraron fuentes oficiales. Como contrapartida, la presión tendrá principalmente tres puntos. Para las provincias que no firmen, el $1^{\circ}$ de enero comenzaría a regir el pacto fiscal de 1993 , por lo que tendrían una reducción mayor de Ingresos Brutos; también podrían dejar de recibir recursos del Fondo Solidario de la soja; y la perspectiva favorable al reclamo de María Eugenia Vidal en la Corte por el Fondo del Conurbano. Sobre este último punto Macri propuso eliminarlo y pasar ese $10 \%$ de Ganancias a la masa coparticipable, con una compensación a Buenos Aires de $\$ 20$ mil millones este año, $\$ 40$ mil millones el próximo y $\$ 65$ mil millones en 2019”33.

La situación para los gobernadores era compleja:

"Ante ese escenario un grupo de gobernadores ya estaba anoche más cerca de confirmar el aval. 'No queda otra, si no terminamos perdiendo peor por los ingresos que eliminan. No tenemos demasiado margen'..."34.

El 15 de noviembre de 2017 a las 11 hs se convocó a una reunión únicamente de gobernadores en la sede del Consejo Federal de Inversiones, dicha reunión demostró las dificultades ante un pronto cierre, debiendo acudir de urgencia el ministro del Interior a reconducir el conflicto e intentar cerrar el acuerdo. Ello se reflejaba de esta manera:

"Fueron seis horas de reunión. El debate fue arduo y por momentos áspero, tanto que después de las 15, cuando los gobernadores llevaban poco más de tres horas encerrados en el séptimo piso del CFI, llegaron Frigerio, su segundo, Sebastián García de Luca, y el secretario de Hacienda, Rodrigo Pena. El encuentro duró otras tres

33 Bravo, Martín (14/11/2017). "Pacto...", ob. cit.

34 Bravo, Martín (14/11/2017). "Pacto...", ob. cit. 
horas. De a uno, los ministros de Economía y Finanzas de las provincias subieron desde el primer piso, donde estaban reunidos desde la mañana, para exponer ante Frigerio y los gobernadores el detalle del impacto fiscal del pacto en sus distritos.... El tema pendiente, sobre el que todavía no hay acuerdo y que Frigerio intentará saldar hoy, es la pretensión del Gobierno de que las provincias renuncien a los juicios contra la Nación. Los gobernadores no están dispuestos a bajar sus reclamos sin ser compensados. Molestos, comparan su situación con la de Vidal, que por mantener la demanda por el Fondo del Conurbano recibirá \$40.000 millones el año que viene y otros $\$ 65.000$ millones en 2019 ”35.

“...el ministro del Interior Rogelio Frigerio se reunió con los gobernadores para intentar destrabar las negociaciones.... Sin embargo, pasadas las 15, Frigerio se sumó a la reunión en el CFI luego de que los gobernadores lo llamaran de urgencia. Según pudo saber ámbito.com, los mandatarios peronistas se encuentran analizando a fondo el ofrecimiento de la Casa Rosada pero quieren más tiempo para sellar el esquema de reformas que se les exige a las provincias. El cúmulo de planteos de las provincias y la necesidad de desmenuzar la letra chica del entendimiento amenaza con dilatar la rúbrica del acuerdo detallado, aunque no se descartaba firmar este jueves un entendimiento macro y general, de 'buena voluntad'..."

"En el transcurso de la tarde, Frigerio modificó alícuotas y progresión de Ingresos Brutos. Como contó Clarín, el tope se flexibiliza. El Comercio quedará, ad eternum, de $5 \%$, al igual que en Telefonía. El tope para Comercio, y a partir de

\footnotetext{
35 Bullrich, Lucrecia (16/11/2017). "El Gobierno intenta destrabar el acuerdo con las provincias". La Nación, recuperado el 16 de diciembre de 2017 de http://www.lanacion.com. ar/2082751-el-gobierno-intenta-destrabar-el-acuerdo-con-las-provincias.

36 Diario Ámbito Financiero (15/11/2017). "Pacto fiscal: Frigerio se reunió con gobernadores y aseguró que están "más cerca de un acuerdo", recuperado el 16 de diciembre de 2017 de http:// www.ambito.com/903560-pacto-fiscal-frigerio-se-reunio-con-gobernadores-y-aseguro-queestan-mas-cerca-de-un-acuerdo
} 
qué año empezaba la baja en Servicios Financieros, marcó uno de los cruces más intensos. En IIBB hubo bilaterales con las provincias que tienen Hidrocarburos que había fijado un régimen tributario que este pacto modificaba. Frigerio accedió al pedido. Para el neuquino Omar Gutiérrez, Alberto Weretilneck de Rio Negro y Pablo González, el vice de Santa Cruz, ese retoque fue clave. La traba es qué hacer con los juicios radicados en la Corte por las provincias. Suman, contó Uñac, 340 mil millones de pesos que las provincias no quieren resignar 'a cambio de nada'. Miguel Lifschitz, de Santa Fe, ya le anticipó a Macri en EEUU que no renunciará a un fallo favorable de los cortesanos.... Todo o nada, dicen en Gobierno: o renuncian todos o no renuncia nadie y siguen los juicios en la Corte. En la charla de Frigerio con los gobernadores se repitió, como un mantra, la frase de 'sacar la litigiosidad de la política'. La cuestión bonaerense, eco de unitarios y federales, estuvo siempre presente porque se discutían sobre fondos para Buenos Aires, pero el gobierno de Vidal no estaba sentado en la mesa. Frigerio-De Luca oficiaron de patrocinantes de la causa bonaerense. 'hace 25 años que me dedico a temas de provincias: en todos los pactos fiscales, la Nación primereó a las provincias'. Esta vez nosotros no queremos que pierdan dijo el ministro luego de escuchar a Insfrán e Schiaretti quejarse de acuerdos en los '90 y en los 2000. Concesiones de ambos lados, el staff oficial confirmó que se coparticipará la recaudación del Revalúo Impositivo -un reclamo de los gobernadores sobre el presupuesto 2018- y que se contemplará el déficit de las cajas previsionales provinciales, un tema hipersensible para trece provincias"37.

En la mañana del 16 de noviembre de 2017 el ministro del Interior Frigerio tendría una reunión con los gobernadores para intentar cerrar el acuerdo, los puntos pendientes "desistimiento

\footnotetext{
37 Ibáñez, Pablo (16/11/2017). "Pacto fiscal: negocian esta mañana en la Rosada para cerrar el acuerdo y firmar con Mauricio Macri". Clarín, recuperado el 16 de diciembre de 2017 de https://www.clarin.com/politica/pacto-fiscal_0_B1wMGH5yz.html
} 
de las demandas provinciales contra el Estado nacional y la fórmula de actualización a los jubilados" ${ }^{\prime 38}$.

Finalmente, ese mismo 16 de noviembre se firma el acuerdo entre la Nación, veintidós provincias y la Ciudad de Buenos Aires. La provincia de San Luís no aceptó firmar, siendo la principal causa no querer renunciar a un juicio ganado. Días más tarde la ministra de Hacienda de San Luís vertió en la prensa fuertes quejas señalando que recibió un "apriete de la Nación y de otras provincias" ${ }^{\prime 39}$.

Resta a esta breve cronología las primeras aplicaciones de los compromisos asumidos, o en términos románticos la prueba de amor de los gobernadores. Esta demostración del compromiso asumido vino de la mano del apoyo de los senadores y diputados en torno a la reforma previsional. En un debate con visiones enfrentadas en torno a si los acuerdos firmados por la Nación y las provincias significaban un ajuste, el oficialismo -de ese momento- dio media sanción a la reforma de la movilidad jubilatoria. Fue con 43 votos afirmativos, 23 negativos y tres abstenciones. Contó con el apoyo de senadores que respondían a los gobernadores peronistas que avalaron el pacto fiscal, que también fue aprobado, al igual que la ley de responsabilidad fiscal ${ }^{40}$.

Pero la situación no fue tan simple en la Cámara de Diputados. La convocatoria a Sesión Especial era el 14 de diciembre de 2017 y destinada a tratar todo el paquete acordado con las provincias, siendo la primera ley que se sometería a votación la

\footnotetext{
38 Telam (16/11/2017). "Frigerio define el alcance del pacto fiscal con los gobernadores" recuperado el 17 de diciembre de 2017 de http://www.telam.com.ar/notas/201711/223278gobernadores-mauricio-macri-pacto-fiscal-rogelio-frigerio.html

39 Telam (22/11/2017). "En San Luis se quejan de un 'apriete' de la Nación y de otras provincias" recuperado el 17 de diciembre de 2017 de http://www.telam.com.ar/notas/201711/225282en-san-luis-se-quejan-de-un-apriete-de-nacion-y-otras-provincias-por-el-pacto-fiscal.html

40 Braslavsky, Guido. (29/11/2017). "El Senado dio media sanción a la reforma previsional y al Pacto fiscal con las provincias". Clarín recuperado el 16 de diciembre de 2017 de https:// www.clarin.com/politica/senado-avanzo-aprobacion-ley-cambia-movilidad-jubilatoria_0_ HJDxFkTgM.html
} 
de Reforma Previsional. Si los gobernadores no conseguían que sus diputados colaboren con el Gobierno nacional, el resto del paquete se caía, es decir el retiro de la demanda por el fondo del Conurbano bonaerense y el reparto de fondos entre las provincias, el "Consenso Fiscal", la Reforma Tributaria y el Revalúo Impositivo $^{41}$. Finalmente, la sesión del día 14 fracasó porque no se pudo lograr el quorum, significando para el gobierno nacional la pérdida de una batalla importante ${ }^{42}$. La nueva sesión se programó para el día 18 de diciembre de 2017, volcando el gobierno nacional toda la presión sobre los gobernadores para que convenzan a sus diputados para dar el quorum. La prensa señalaba:

\begin{abstract}
"Tras el escándalo del jueves pasado, la Casa Rosada intensificó la presión a los gobernadores para que garanticen la presencia de los diputados de sus provincias en el Congreso. El oficialismo espera sumar a tres representantes de Salta, dos de Entre Ríos, uno de Neuquén y otro de Corrientes, que estuvieron ausentes en la tensa sesión del jueves. La mayoría de esos legisladores integran Argentina Federal, que responde a los gobernadores. El interbloque, que conduce el salteño Pablo Kosiner, garantiza en total la presencia de 25 diputados para dar quorum. Con ese apoyo, el Gobierno no tiene dudas de que sentará entre 135 o 137 integrantes de la Cámara baja en sus bancas para arrancar el debate en el recinto" 43 .
\end{abstract}

\footnotetext{
41 Argento, Analia (13/12/2017). "El Ejecutivo advirtió que si no se aprueba la Reforma Previsional se caerá el pacto fiscal". Infobae recuperado el 17 de diciembre de 2017 de https://www.infobae.com/politica/ 2017/12/13/el-ejecutivo-advirtio-que-si-no-se-apruebala-reforma-previsional-se-caera-el-pacto-fiscal/

42 La sesión del día 14 de diciembre estuvo precedida de un inusual operativo de seguridad llevado adelante por la ministra de seguridad con la Gendarmeria Nacional, siendo los hechos ocurridos vergonzosos y darían por si solos a un análisis particular en relación con el actuar de las fuerzas de seguridad en hechos de protesta social.

43 La Nación (18/12/2017). "El quorum, la clave de la sesión por la reforma previsional: el cálculo oficial y la desconfianza del FPV" recuperado del 12 de enero de 2018 de http://www. lanacion.com.ar/2092463-la-batalla-por-el-quorum-la-clave-de-la-sesion-por-la-reformaprevisional-el-calculo-oficial-y-la-desconfianza-del-fpv.
} 
Para sumar al cumplimiento del compromiso en forma previa existió una foto importante que no pasó inadvertida:

"Fue un gesto contundente de apoyo a la reforma previsional pero un gesto que costó armar... no hubo sonrisas en la foto, excepto la del jujeño Morales" ${ }^{44}$.

Los medios titulaban "El silencio de los gobernadores que dieron quórum y la foto que necesitaba el Gobierno" ${ }^{45}$,"Reforma previsional: 12 gobernadores se mostraron juntos para apoyar el proyecto" ${ }^{46}$, "Trece gobernadores manifestaron su apoyo a la reforma previsional" ${ }^{47}$, "Antes de la sesión, Frigerio y Peña armaron foto de apoyo de gobernadores a la reforma" ${ }^{\not 8}$.

Luego de una maratónica sesión, con graves incidentes en las calles, se aprobó la reforma previsional, dando cumplimiento los gobernadores a una parte importante del acuerdo.

En la sesión del día 21 de diciembre de 2017 se trató en la Cámara de Diputados el "Consenso Fiscal" «9, resultando el mismo aprobado por las mayorías necesarias junto a otras leyes tributarias vinculadas al citado consenso.

\footnotetext{
44 Argento, Analia (18/12/2017). "El silencio de los gobernadores que dieron quórum y la foto que necesitaba el Gobierno". Infobae recuperado el 12 de enero de 2018 de https://www. infobae.com/politica/2017/ 12/18/el-silencio-de-los-gobernadores-que-dieron-quorum-y-lafoto-que-necesitaba-el-gobierno/.

45 Argento, Analia. (18/12/2017). "El silencio...", ob. cit.

46 Clarin. (18/12/2017). "Reforma previsional: 12 gobernadores se mostraron juntos para apoyar el proyecto", recuperado el 12 de enero de 2018 de https://www.clarin.com/politica/ reforma-previsional-12-gobernadores-mostraron-juntos-apoyar-proyecto_0_BkqaBOBGM.html.

47 LMNeuquen.com. (18/12/2017). “Trece gobernadores manifestaron su apoyo a la reforma previsional" recuperado el 12 de enero de 2018 de https://www.Imneuquen.com/trecegobernadores-manifestaron-su-apoyo-la-reforma-previsional-n574850.

48 Diario Ámbito Financiero. (18/12/2017). “Antes de la sesión, Frigerio y Peña armaron foto de apoyo de gobernadores a la reforma", recuperado el 12 de enero de 2018 de http:// www.ambito.com/906858-antes-de-la-sesion-frigerio-y-pena-armaron-foto-de-apoyo-degobernadores-a-la-reforma.

49 Honorable Cámara de Diputados de la Nación. (2017). "SESIÓN COMPLETA 2da PARTE: H. Cámara de Diputados de la Nación - 21 de Diciembre de 2017" [video]. Publicado el 26 diciembre de 2017, consultado el 22 de enero de 2017 de https://youtu.be/IJRoSjOYppk?t=10366
} 


\section{IV.2. Elementos de presión y concesión}

Los actores no llegan desprovistos a una negociación, sino por el contrario cargan sus elementos de presión y de concesión. Podemos definir a los elementos de presión como aquellas cosas o circunstancias que son apreciadas por la contraparte como peligrosas y que normalmente en una toma de decisiones racional intentará no perderlas o que no ocurran. Podemos definir a los elementos de concesión como aquellas cosas o circunstancias que son apreciadas por la contraparte como una ventaja y que normalmente en una toma de decisiones racional intentará obtenerlas o que ocurran.

Es útil para el análisis repasar los elementos con que contaban la Nación y las provincias.

\section{IV.2.1. Suspensión del Pacto Fiscal del año 1993 (Pacto Fiscal II)}

El Pacto Federal fiscal del año $1993^{50}$, tenía una serie de aspectos que las provincias y la Nación debían cumplir en materia tributaria. A pocos años de su firma el mismo se tornó en incumplible para las provincias y para la Nación, decidiendo ambas partes postergar su cumplimiento ${ }^{51}$, dicha prorroga vencía el 31 de diciembre de $2017^{52}$. La fijación de nuevos plazos de vencimiento habitualmente se realiza en las leyes que prorrogan impuestos, las que se envían en conjunto con el presupuesto. Este hecho no ocurrió en septiembre de 2017.

Así se vislumbraba ello en la prensa "El Gobierno se queda con la carta del Pacto Fiscal para negociar en 2018

\footnotetext{
50 Poder Ejecutivo Nacional. Decreto 19/94 recuperado el 4 de enero de 2018 de http://www. cfi.gov.ar/docs/ Pactoll.pdf

51 Comisión Federal de Impuestos. Resolución General Interpretativa 35/2014, recuperada el 4 de enero de 2018 de http://www.cfi.gov.ar/docs/resoluciones/rgi/r_g_i_n_35_2014.pdf, y Resolución General Interpretativa 36/2017 recuperada el 4 de enero de 2018 de http://www. cfi.gov.ar/docs/resoluciones/reservadas/r_g_i_n_36_2017.pdf .

52 La Ley 27.199 prorrogó el cumplimiento del Pacto Fiscal II hasta el 31 de diciembre de 2017.
} 
con provincias" 53 , "El pacto fiscal de 1993 acecha a los mandatarios" ${ }^{\prime 4}$.

Esto era un elemento de presión para las provincias, pero sin embargo la aplicación irrestricta del pacto implicaba también un riesgo para la Nación la que debía bajar el Impuesto al Valor Agregado a una tasa efectiva del dieciocho por ciento. Ese hecho no fue valorado por los gobernadores en el proceso de negociación.

\section{IV.2.2. Fondo del Conurbano}

La provincia de Buenos Aíres en el año 2016 inició un juicio contra la Nación por un ajuste de fondos coparticipable y en dicho proceso la Nación citó a las restantes veintidós provincias y a la Ciudad Autónoma de Buenos Aires. Los traslados de las demandas se terminaron de contestar por parte de las provincias en octubre ${ }^{55}$ de 2017, quedando el expediente en estado para resolver la cautelar solicitada por la Provincia de Buenos Aires, lo cual implicaba una actualización del fondo del Conurbano Bonaerense.

El día 6 de noviembre de 2017 la Gobernadora de la provincia de Buenos Aires y el presidente de la Corte Suprema de Justicia de la Nación tuvieron una reunión en la que abordaron temas vinculados a la lucha contra el narcotráfico y reformas en el sistema judicial que encararía la provincia de Buenos Aires. Sin que exista reconocimiento oficial, otros de los temas que se trató en dicha reunión -conforme lo expuso la prensa- habría sido el juicio que tenía la corte para resolver. Así se vio reflejado: "Vidal

53 Dalto, Veronica. (02/10/2017). "El Gobierno se queda con la carta del Pacto Fiscal para negociar en 2018 con provincias". El Cronista, recuperado el 16 de diciembre de 2017 de https://www.cronista.com/economiapolitica/El-Gobierno-se-queda-con-la-carta-del-PactoFiscal-para-negociar-en-2018-con-provincias-20171002-0038.html

54 Bullrich, Lucrecia. (09/11/2017). "El pacto fiscal de 1993 acecha a los mandatarios". La Nación, recuperado el 17 de diciembre de 2017 de "http://www.lanacion.com.ar/2080597el-pacto-fiscal-de-1993-acecha-a-los-mandatarios

55 La causa puede consultarse en http://scw.pjn.gov.ar/scw/expediente.seam?cid=2320919 
se reunió con Lorenzetti y dijo que el reclamo por el Fondo del Conurbano 'es justo y legítimo"”56, "Lorenzetti recibió a Vidal, en medio de la tensión por el reclamo del Fondo del Conurbano" 57 , "En medio de la tensión por el reclamo del Fondo del Conurbano, Ricardo Lorenzetti recibió a María Eugenia Vidal"58, "Malestar en las provincias por la foto de Vidal con Lorenzetti" y "Alerta entre los gobernadores por la foto María Eugenia Vidal-Ricardo Lorenzetti" $"$.

Esta reunión y su foto fue interpretada por los gobernadores como un guiño favorable de la CSJN, entendiendo que era altamente probable -o seguro- que la medida cautelar sería resuelta a favor de la provincia de Buenos Aires, aun cuando no fuera así, lo importante para el análisis que estamos realizando es la percepción de los actores. Ello fue puesto de manifiesto en varias alocuciones en la Cámara de Diputados ${ }^{61}$ cuando se trató el "Consenso Fiscal" y la sanción del presupuesto 2018.

\footnotetext{
56 IProfesional. (06/11/2017). "Vidal se reunió con Lorenzetti y dijo que el reclamo por el Fondo del Conurbano 'es justo y legítimo'.", recuperado el 16 de diciembre de 2017 de http:// www.iprofesional.com/notas/258400-Iorenzetti-corte-suprema-tipo-de-cambio-vidal-tarifatribunal-fiscal-de-la-nacion-tribunales-Vidal-se-reunio-con-Lorenzetti-y-dijo-que-el-reclamopor-el-Fondo-del-Conurbano-es-justo-y-legitimo?page_y=0

57 La Gaceta de Salta. (07/11/2017). "Lorenzetti recibió a Vidal, en medio de la tensión por el reclamo del Fondo del Conurbano", recuperado el 16 de diciembre de 2017 de https:// www.lagacetasalta.com.ar/ nota/93040/actualidad/lorenzetti-recibio-vidal-medio-tensionreclamo-fondo-conurbano.html

58 Bravo, Martín. (06/11/2017). "En medio de la tensión por el reclamo del Fondo del Conurbano, Ricardo Lorenzetti recibió a María Eugenia Vidal". Clarín, recuperado el 16 de diciembre de 2017 de https://www.clarin.com/politica/medio-tension-reclamo-fondo-conurbano-ricardolorenzetti-recibio-maria-eugenia-vidal_0_S1GwlIARZ.html

59 Bullrich, Lucrecia. (08/11/2017). "Malestar en las provincias por la foto de Vidal con Lorenzetti". La Nación, recuperado el 16 de diciembre de 2017 de http://www.lanacion.com. ar/2080265-malestar-en-las-provincias-por-la-foto-de-vidal-con-lorenzetti.

60 Ibañez, Pablo. (07/11/2017). “Alerta entre los gobernadores por la foto María Eugenia VidalRicardo Lorenzetti". Clarín, recuperado el 16 de diciembre de 2017. https://www.clarin.com/ politica/alerta-gobernadores-foto-maria-eugenia-vidal-ricardo-lorenzetti_0_S15ss5JkM.html.

61 Véase versión taquigráfica de la sesión correspondiente al Período $135^{\circ}$ - $26^{\circ}$ Reunión $3^{\circ}$ Sesión Extraordinaria - 21 de diciembre de 2017 consultada en http://www4.hcdn.gob.ar/ sesionesxml/provisorias/135-26.htm
} 
Esta demanda, aun cuando era de la provincia de Buenos Aires, fue un elemento de presión que utilizó la Nación. La prensa lo reflejaba de esta forma "La cuestión bonaerense, eco de unitarios y federales, estuvo siempre presente porque se discutían sobre fondos para Buenos Aires pero el gobierno de Vidal no estaba sentado en la mesa. Frigerio-De Luca oficiaron de patrocinantes de la causa bonaerense"62.

Por otra parte, y como contracara de dicho elemento de presión, la Nación ofrecía hacerse cargo del costo económico que implicaba otorgarle sesenta y cinco mil millones en la medida en que se firmará el pacto bajo las condiciones propuestas.

\section{IV.2.3. Fondo Federal Solidario (Fondo de la soja)}

En el año 2009, luego de perder el gobierno de la Presidenta Fernandez de Kirchner una dura batalla en el Congreso por las retenciones móviles y frente a la puja de diversas asociaciones rurales por la derogación de las retenciones, se dicta un decreto de necesidad y urgencia por el cual se crea el Fondo Federal Solidario y se comienza a coparticipar lo recaudado por retenciones a las exportaciones de soja neutralizando, el entonces gobierno nacional, cualquier apoyo político a la eliminación del sistema. Las retenciones a las exportaciones son recursos que por disposiciones constitucionales pertenecen en forma exclusiva a la Nación y no son coparticipables, por lo tanto su distribución es una gracia que se concede a las provincias.

Otro de los elementos que tenía el gobierno nacional como elemento de presión era no dar participación en la distribución del Fondo Federal Solidario a los que no firmaran el acuerdo. Más aún este fondo quedó como un elemento de presión para los que habiendo firmado el pacto no lo cumplan ${ }^{63}$.

\footnotetext{
62 Ibáñez, Pablo. (16/11/2017). "Pacto...", ob. cit.

63 Sobre fines de enero de 2018 la Nación empezó a retener fondos de aquellas provincias que no habían ratificado legislativamente el "Consenso Fiscal"., véase: 1) Telam. (25/01/2018) "Dura advertencia de Dujovne a los gobernadores que no cumplan el pacto fiscal". La Voz, recuperado el 5 de febrero de 2018 de http://www.lavoz.com.ar/politica/
} 


\section{IV.2.4. Juicios de las provincias}

Las provincias tenían iniciados varios reclamos contra la Nación por incumplimiento de acuerdo o violaciones constitucionales en cuanto a los fondos coparticipados. Algunos de estos reclamos ya tenían sentencia firme, tal como es el caso de las provincias de Santa Fe y San Luís.

La pretensión del gobierno nacional era cerrar esos reclamos sólo a cambio de que Buenos Aires retire su reclamo, y la Nación compense a Buenos Aires.

Esto sin lugar a duda era un elemento de presión que tenían algunas provincias y de concesión para otras cuyos juicios estaban lejos aún de ser resueltos.

\section{IV.2.5. Baja de los tributos}

En cuanto a la baja de los tributos, esto era un elemento de alto valor para las provincias que estaban en mejores condiciones fiscales. El valor estaba dado por la suma que implicaba resignar y dejar de recaudar.

Los recursos provinciales resultan escasos. Cuesta mucho esfuerzo y tiene un alto costo político tener una buena recaudación local, es por ello que muchas provincias por desidia o por no pagar el costo político tienen una recaudación muy baja.

Por ello encontramos un grupo de provincias entre las cuales lo requerido implicaba un alto costo de concesión y para otras era un elemento de bajo costo de concesión.

Para la provincia que más recauda -provincia de Buenos Aires- el costo se veía neutralizado por la enorme transferencia de recursos que implicaba el acuerdo vinculado al Fondo del Conurbano Bonaerense.

\footnotetext{
dura-advertencia-de-dujovne-los-gobernadores-que-no-cumplan-el-pacto-fiscal y; 2) El Litoral. (27/01/2018). "Nación retiene fondos a provincias que aún no avalaron el Pacto Fiscal, entre ellas Corrientes", recuperado el 5 de febrero de 2018 de http://www.ellitoral.com. ar/nota/2018-1-27-4-0-0-nacion-retiene-fondos-a-provincias-que-aun-no-avalaron-el-pactofiscal-entre-ellas-corrientes .
} 
Como herramienta de presión para que las provincias firmen la baja solicitada el gobierno nacional tenía la entrada en vigor del Pacto Federal Fiscal de 1993.

\section{IV.2.6. Votos en el congreso}

Uno de los mayores elementos con los que contaban algunos gobernadores, eran diputados y senadores que en forma más o menos disciplinada votaran de acuerdo con lo que hubiera negociado el Gobernador de cada provincia. Aun cuando esta situación no es lineal, en el sentido que el mero acuerdo del Gobernador implicara obtener los votos, en muchos casos los gobernadores tienen fuerte ascendencia sobre los diputados y senadores nacionales.

\section{IV.3. Actores}

Los actores del proceso son de un lado el gobierno Nacional y del otro los gobernadores y el jefe de gobierno de la Ciudad Autónoma de Buenos Aires.

Resulta adecuado recordar que la elección de los gobernadores esta -en la mayoría de los casos- alineada con la elección presidencial, por tanto, la pertenencia político partidaria está vinculada a la elección del año 2015.

\begin{tabular}{|l|l|l|l|}
\hline \multicolumn{1}{|c|}{ Provincia } & \multicolumn{1}{c|}{ Nombre } & \multicolumn{2}{c|}{ Partido } \\
\hline Buenos Aires & $\begin{array}{l}\text { María Eugenia } \\
\text { Vidal }\end{array}$ & Cambiemos & PRO - Cambiemos \\
\hline Catamarca & Lucía Corpacci & PJ & PJ - FPV \\
\hline Chaco & Domingo Peppo & PJ & PJ - Frente Chaco Merece \\
Chús
\end{tabular}




\begin{tabular}{|c|c|c|c|}
\hline Formosa & Gildo Insfrán & PJ & PJ - FPV \\
\hline Jujuy & Gerardo Morales & Cambiemos & UCR - Cambia Jujuy \\
\hline La Pampa & Carlos Verna & PJ & PJ - Peronismo Pampeano \\
\hline La Rioja & Sergio Casas & PJ & PJ - FPV \\
\hline Mendoza & Alfredo Cornejo & Cambiemos & UCR - Cambia Mendoza \\
\hline Misiones & Hugo Passalacqua & P. Provincial & $\begin{array}{l}\text { Partido de la Concordia } \\
\text { Social - Frente Renovador de } \\
\text { la Concordia }\end{array}$ \\
\hline Neuquén & Omar Gutiérrez & P. Provincial & MPN \\
\hline Río Negro & \begin{tabular}{|l|} 
Alberto \\
Weretilneck
\end{tabular} & P. Provincial & $\begin{array}{l}\text { Frente Grande - Juntos } \\
\text { Somos Río Negro }\end{array}$ \\
\hline Salta & $\begin{array}{l}\text { Juan Manuel } \\
\text { Urtubey }\end{array}$ & PJ & $\begin{array}{l}\text { PJ - Frente Justicialista } \\
\text { Renovador para la Victoria }\end{array}$ \\
\hline San Juan & Sergio Uñac & PJ & PJ - FPV \\
\hline San Luis & $\begin{array}{l}\text { Alberto Rodríguez } \\
\text { Saá }\end{array}$ & PJ & PJ - Compromiso Federal \\
\hline Santa Cruz & Alicia Kirchner & PJ & PJ - FPV \\
\hline Santa Fe & Miguel Lifschitz & P. Provincial & Socialista - FPCyS \\
\hline $\begin{array}{l}\text { Santiago del } \\
\text { Estero }\end{array}$ & Gerardo Zamora & P. Provincial & FCpS \\
\hline $\begin{array}{l}\text { Tierra del } \\
\text { Fuego }\end{array}$ & Rosana Bertone & PJ & PJ - FPV \\
\hline Tucumán & Juan Luis Manzur & PJ & PJ - FPV \\
\hline $\begin{array}{l}\text { Ciudad } \\
\text { Autónoma de } \\
\text { Buenos Aires } \\
\end{array}$ & $\begin{array}{l}\text { Horacio Rodríguez } \\
\text { Larreta }\end{array}$ & Cambiemos & PRO - Unión Pro \\
\hline
\end{tabular}

Elaboración propia. Se utiliza gris oscuro para los integrantes de la alianza “Cambiemos" con origen en la Unión Cívica Radical y gris claro para gobernadores con origen en el PRO.

A los fines del análisis podemos agruparlos bajo tres grupos de actores, según esta clasificación: a) Cambiemos: gobernadores que cuyo triunfo estuvo vinculado al triunfo del ex presidente Marcri; b) PJ: gobernadores afines al Partido Justicialista que incluye en este caso a los que llegaron de la mano del Frente Para la Victoria, y; c) Partido Provincial: gobernadores que tienen partidos provinciales con peso propio independientemente 
de las alianzas que hayan realizado para las elecciones presidenciales.

De esta clasificación tenemos entonces: cinco (5) gobernadores de Cambiemos, catorce (14) gobernadores del PJ, y cinco (5) gobernadores de Partidos Provinciales.

Si estos grupos además del origen partidario lo categorizamos como amigos y no amigos, en cuanto al comportamiento colaborativo en la negociación así quedaría la clasificación:

\begin{tabular}{|l|l|}
\hline \multicolumn{1}{|c|}{ Provincia } & Amigos y No amigos \\
\hline Buenos Aires & Cambiemos Amigo \\
\hline Catamarca & PJ Amigo \\
\hline Chaco & PJ Amigo \\
\hline Chubut & PJ \\
\hline Córdoba & PJ Amigo \\
\hline Corrientes & Cambiemos Amigo \\
\hline Entre Ríos & PJ Amigo \\
\hline Formosa & PJ \\
\hline Jujuy & Cambiemos Amigo \\
\hline La Pampa & PJ \\
\hline La Rioja & PJ \\
\hline Mendoza & Cambiemos Amigo \\
\hline Misiones & P. Provincial Amigo \\
\hline Neuquén & P. Provincial Amigo \\
\hline Río Negro & P. Provincial Amigo \\
\hline Salta & PJ Amigo \\
\hline San Juan & PJ \\
\hline San Luis & PJ \\
\hline Santa Cruz & PJ \\
\hline Santa Fe & P. Provincial \\
\hline Santiago del Estero & P. Provincial \\
\hline Tierra del Fuego & PJ Amigo \\
\hline Tucumán & PJ Amigo \\
\hline Ciudad Autónoma de Buenos Aires & Cambiemos Amigo \\
\hline & \\
\hline
\end{tabular}


De esta forma entre Cambiemos Amigo, Partido Justicialista Amigo y Partido Provincial Amigo sumamos a quince (15) gobernadores, y el resto no amigo alcanzaría a nueve (9) gobernadores.

En su análisis de las coaliciones Altavilla agrupa a los gobernadores por su pertenencia a provincias chicas y grandes, integrando el lote de provincias grandes Buenos Aires, Santa Fe, Córdoba y Mendoza a lo que agrega además a la Ciudad Autónoma de Buenos Aires.

Estas cinco jurisdicciones concentran el 66,70\% de la población total del país ${ }^{64}$, y cuentan con el 55,25\% del total de bancas en el congreso lo cual muestra una subrepresentación en relación con la población. En el senado estas cinco jurisdicciones alcanzan al 20,83 \% del total de bancas. Si bien las conclusiones de Altavilla en cuanto a la sobre representación de las provincias chicas hoy se mantiene invariable, las coaliciones no se conformaron por el tamaño de las provincias sino estuvieron determinada por un grado de acercamiento o no hostilidad de un grupo de provincias dirigidas por gobernadores con distinta pertenencia partidaria al ex presidente Macri.

En este caso, aun cuando el análisis es similar las constelaciones que se conformaron fueron distintas. No constituye un dato menor que cinco de las tres provincias grandes ${ }^{65}$ son gobernadas por partidos que forman parte de la alianza "Cambiemos" del ex presidente Macri, y no ha sido un dato menor que en las legislativas de 2017 la alianza "Cambiemos" se impuso en esas cinco provincias grandes.

De los diez (10) gobernadores que han tenido un grado de acercamiento o no hostilidad sólo cuatro de ellos obtuvieron triunfos en las legislativas de medio término (Misiones, Río Negro, Tierra del Fuego y Tucumán) en las otras seis (6)

64 INDEC. "Censo del año 2010", información consultada en https://www.indec.gov.ar/ censos_total_pais.asp? id_tema_1=2\&id_tema_2=41\&id_tema_3 $=135 \& t=3 \& s=0 \& c=2010$ 65 Buenos Aires, Mendoza y Ciudad de Buenos Aires. 
provincias ganó "Cambiemos" (Catamarca, Chaco, Córdoba, Entre Ríos, Neuquén y Salta).

\section{IV.3.1. Fortalezas y debilidades. Mejor alternativa a un acuerdo negociado}

Leiras afirma: “... los gobiernos provinciales son económicamente dependientes y débiles, pero políticamente autónomos y fuertes" ${ }^{66}$, describiendo autonomía y fortaleza como:

"la capacidad de los gobiernos provinciales para orientar en su favor los resultados de las negociaciones con el gobierno central. Recurriendo al lenguaje de las teorías racionalistas de la negociación, decir que los gobiernos provinciales son fuertes vis-a-vis con el gobierno nacional equivale a afirmar que el valor de sus opciones de salida, o 'exteriores' es alto; esto es que, si una negociación fracasa, no quedan en una posición vulnerable ni se compromete su supervivencia" ${ }^{67}$.

Pero por otra parte tal como señala Leiras:

"...la dependencia de los gobiernos provinciales respecto de las transferencias del gobierno nacional es, para la mayoría de las provincias, muy alta y tiende a crecer... Recurriendo nuevamente a la analogía con la teoría de la negociación, propongo que, en el caso de las negociaciones fiscales, para la mayoría de los gobiernos provinciales el valor de opción exterior es bajo. Todos los gobiernos provinciales son, como hemos visto, política y electoralmente autosuficientes, lo que implica que pueden sobrevivir a la ruptura de una negociación electoral. En el plano fiscal no ocurre lo mismo ${ }^{68} \ldots$ si una negociación fiscal con el gobierno nacional fracasa, los

\footnotetext{
66 Leiras, Marcelo (2013). "Las contradicciones aparentes del federalismo argentino y sus consecuencias políticas y sociales". En Acuña, Carlos H. (compilador). ¿Cuánto importan las Instituciones?. Buenos Aires. Ed. Siglo XXI Editores, pp. 209-245. La cita es de p. 229.

67 Leiras, Marcelo (2013). "Las contradicciones ... ", pp. 229-230.

68 Leiras, Marcelo (2013). "Las contradicciones ..., p. 233.
} 
gobiernos provinciales quedan expuesto a desequilibrios financieros, son vulnerables a conflictos laborales con el sector público, y quedan librados a sus capacidades de recaudación, en general limitada, para realizar inversiones electoralmente rentables. En esto consiste su vulnerabilidad financiera, y estos son los motivos que pueden llevarlos a intercambiar sus capacidades de movilización electoral y su influencia sobre los legisladores elegidos en las provincias a cambió de la asistencia financiera del gobierno central"69.

En lo político, el gobierno nacional contaba con ciento ocho (108) diputados correspondientes a distintas provincias, necesitando ciento veintinueve (129) diputados para obtener el quorum.

La necesidad del gobierno nacional para lograr la aprobación del paquete de leyes que pretendía asegurar con el "Consenso Fiscal" era el mejor recurso que tenían las provincias en su negociación. Por su parte, el gobierno nacional a cambio tenía el dinero del fondo de la soja para quienes cooperen.

Tal como explica Leiras la opción de una salida no negociada para la mayoría de las provincias no era una opción viable, sólo San Luís que cuenta con una provincia sin deudas, ordenada ${ }^{70}$ y había obtenido una sentencia favorable en la Cortes Suprema de Justicia de la Nación, se encontraba en una posición que permitía tener una mejor alternativa al acuerdo que se negociaba, en otros términos, retirarse de la negociación sin firmar. En una situación parecida se encontraba la provincia de La Pampa que firmó el acuerdo, pero no lo ratificó legislativamente.

Del otro lado de la mesa el gobierno nacional, victorioso en las elecciones, no tenía la posibilidad de imponer en el congreso una mayoría que permitiera aprobar los proyectos esenciales

\footnotetext{
69 Leiras, Marcelo (2013). "Las contradicciones ..., " p. 238.

70 El Diario de la República (30/11/2017). “Alberto: “No pasará nada por no firmar, las obras continuarán", recuperado el 17 de diciembre de 2017 de https://www.eldiariodelarepublica. com/nota/2017-11-30-20-56-26-alberto-rodriguez-saa-el-consenso-fiscal-solo-beneficia-ala-nacion-y-a-buenos-aires.
} 
-entre ellos la reforma previsional- por lo cual necesitaba del apoyo de legisladores provinciales pertenecientes a otros espacios políticos, teniendo también un alto costo una salida que implicará no alcanzar un acuerdo negociado.

El alto costo de esta salida pudo apreciarse cuando ante el fracaso de la sesión del día 14 de diciembre se especuló en sacar la reforma previsional utilizando el mecanismo de los decretos de necesidad y urgencia, lo cual tuvo un claro rechazo aún en el propio partido de gobierno. ${ }^{71}$

$\mathrm{Ni}$ las provincias ni el gobierno nacional podían asignar un alto valor a una salida no negociada, la cual para ambos se percibía como una resolución que acarrearía un gran costo.

\section{IV.3.2. Constelación de actores colaborativos}

Dentro de la constelación de provincias que adoptaron una actitud colaborativa en el proceso de negociación observamos que dicha actitud tuvo distintas fuentes. En las provincias de Catamarca, Chaco, Córdoba, Entre Ríos, Neuquén y Salta la actitud de colaboración parecería que no sólo estuvo influida por la necesidad de recursos sino también por la reciente derrota electoral sufrida en las elecciones de medio término. En el caso de Misiones, Río Negro, Tierra del Fuego y Tucumán las necesidades económicas y las graves consecuencias de un no acuerdo han llevado a adoptar una actitud cooperativa en pos de obtener algún beneficio en la negociación o bien evitar mayores pérdidas.

Logrado un acuerdo con 15 gobernadores al resto -excepto lo que se explicó de San Luis- no le quedaban más alternativas que sumarse dado que no poseían una alternativa no negociada.

\footnotetext{
71 Expresaba la prensa "La diputada de la Coalición Cívica y socia de Cambiemos Elisa Carrió advirtió que realizar la reforma previsional por DNU 'violaría gravemente la Constitución Nacional'. Es ante los rumores que mencionan la posibilidad de que el presidente Mauricio Macri disponga de la iniciativa por decreto ante la caída de la sesión para tratar el proyecto en Diputados". Diario Ámbito Financiero. (14/12/2017). "Carrió advierte que una reforma previsional por DNU "violaría gravemente la Constitución", recuperado el 16 de diciembre de 2017 de http://www.ambito.com/906628-carrio-advierte-que-una-reforma-previsional-pordnu-violaria-gravemente-la-constitucion.
} 
El apoyo se concretó al tiempo de tratarse la reforma previsional, con lo siguientes votos de diputados que no pertenecían a la coalición de gobierno:

\begin{tabular}{|l|c|}
\hline \multicolumn{1}{|c|}{ Provincia } & Votos \\
\hline Catamarca & 2 \\
\hline Chaco & 1 \\
\hline Córdoba & 4 \\
\hline Entre Ríos & 2 \\
\hline Misiones & 5 \\
\hline Neuquén & 1 \\
\hline Salta & 2 \\
\hline Santiago del Estero & \\
\hline Tucumán & 1 \\
\hline & 2 \\
\hline
\end{tabular}

Estos veinte diputados nacionales junto a los ciento siete diputados de cambiemos lograron la mayoría de ciento veintisiete (127) diputados que aprobaron la reforma previsional.

De esta forma el acuerdo firmado fue cumplido, logrando el gobierno nacional obtener los votos necesarios para la ansiada reforma previsional.

\section{IV.3.3. Percepciones y preferencias}

Las percepciones y preferencias de los actores involucrados son distintas y diversas. El Presidente tiene a su cargo la administración del país prefiriendo llevar adelante su plan de gobierno en la forma que el partido gobernante ha planificado. En el caso el plan de gobierno del ex presidente estaba cimentado sobre principios neoliberales lo que implica, la reducción del gasto social (jubilaciones, subsidios, etc.), reducción del Estado, y la reducción de impuestos. Sobre estos ejes giró el acuerdo a discutir. La victoria electoral, en especial en las cinco provincias

72 Sobre el último momento la gobernadora Ledesma retiro los votos de apoyo comprometido, pero curiosamente la diputada Navarro dio su voto afirmativo para la aprobación del proyecto. 
más grandes, permitió al entonces gobierno nacional percibir un poder de negociación superior al que tenía y se percibían como políticamente débiles la mayoría de los gobiernos provinciales.

Por su parte los gobernadores no oficialistas se vieron impactados por el amplio triunfo electoral de "Cambiemos", lo cual llevó a que un importante grupo de gobernadores adoptara una actitud colaborativa aun cuando hubieran resultado victoriosos en sus provincias. En cuanto a las preferencias, la capacidad económica con que cuentan las provincias es limitada, y en un esquema de reducción de impuestos las preferencias se volcaban a perder lo menos posible y que dicha perdida sea lo más gradual posible.

Corresponde observar que los gobernadores asumieron compromisos hasta el año 2022 cuando sus gestiones culminan en el año 2019, tratando que los efectos más importantes del pacto -en cuanto a la perdida de recursos- se produzcan luego de la culminación de sus mandatos. Esto puede apreciarse como una actitud oportunista que buscó diferir los efectos del "Consenso Fiscal" a los futuros gobernadores. Las instituciones federales y las instituciones provinciales no limitan a que los gobernadores asuman compromisos más allá del tiempo de su mandato.

\section{IV.4. Modos de interacción. Aplicación de la teoría de los juegos}

Continuando con la hipótesis de Altavilla este explica “... intentaremos aplicar... la "Batalla de los Sexos" ... para explicar el fenómeno político bajo análisis. Por cuestiones de espacio, sólo explicaremos este juego luego de considerar los modos de interacción."’3

Los modos de interacción son la forma en que esos actores se relacionan. Las interacciones se desarrollan de acuerdo con las reglas institucionales, que determinan los modos y formas de proceder y cómo han de tomar la decisión que resuelva el caso.

73 Altavilla, Cristian (2012). "Procesos ...", ob . cit., p. 178. 
El modo de interacción utilizado por Altavilla se trata de un acuerdo negociado. Ello parece adecuado toda vez que los pactos fiscales implican en todos los casos reformas tributarias que no pueden ser impuestas en forma unilateral por el diseño de estado federal en el cual se desenvuelven los actores. Así se aprecia que el diseño institucional estipula que la negociación se debe llevar adelante con los gobernadores ${ }^{74}$ y que cualquier acuerdo en relación con afectaciones específicas de fondos coparticipables requerirá de mayorías especiales ${ }^{75}$, y que todos los acuerdos con relación a tributos provinciales requerirán el acuerdo de cada provincia dado que ellas tienen autonomía para darse sus propias instituciones. ${ }^{76}$

Los pactos fiscales han sido caracterizados jurídicamente como tratados celebrados entre la nación y las provincias, denominados comúnmente como federalismo de concertación. ${ }^{77}$

74 La Constitucion Nacional establece "Artículo 128.- Los gobernadores de provincia son agentes naturales del Gobierno federal para hacer cumplir la Constitución y las leyes de la Nación."

75 El art. 75 inc. 3 de la Constitución Nacional establece entre las facultades del Congreso “3. Establecer y modificar asignaciones específicas de recursos coparticipables, por tiempo determinado, por ley especial aprobada por la mayoría absoluta de la totalidad de los miembros de cada Cámara."

76 Constitucion Nacional, artículos 5, 121 y 122.

77 La CSJN en autos "Asociación de Grandes Usuarios de Energía Eléctrica de la República Argentina (AGUEERA) c/ Buenos Aires, Provincia de y otro s/ acción declarativa" en sentencia de fecha 19 de agosto de 1999, dijo "4º Que el Pacto comporta por sus alcances y contenido la manifestación positiva del Ilamado federalismo de concertación tendiente a -según se expresa- establecer mediante la participación concurrente del Estado Nacional y las provincias un programa, destinado como en el caso, a adoptar una política uniforme que armonice y posibilite "la finalidad común de crecimiento de la economía nacional y de reactivación de las economías regionales". Tal aspiración recogería la vocación de la Constitución Nacional creadora -según lo expresó esta Corte en Fallos: 178:9 de "una unidad no por supresión de las provincias...sino por conciliación de la extrema diversidad de situación, riqueza, población y destino de los catorce estados y la creación de un órgano para esa conciliación, para la protección y estímulo de los intereses locales, cuyo conjunto se confunde con la Nación misma". Se trataba, recordaba la sentencia, de consagrar el principio de "hacer un solo país para un solo pueblo". Ese pacto, como las demás creaciones legales del federalismo de concertación, configura el derecho intrafederal (Fallos: 314:862) y se incorpora una vez ratificado por la legislatura al derecho público interno de cada estado provincial aunque con la diversa jerarquía que le otorga su condición de ser expresión de la voluntad común de los órganos superiores de nuestra organización constitucional: nación y 


\section{IV.4.1 La batalla de los sexos}

El juego que explica el modo en que se llegan a estos acuerdos, según la hipótesis en análisis, es el conocido como la batalla de los sexos.

Antes de avanzar con la aplicación del juego corresponde realizar una breve introducción. La Teoría de los Juegos es un novedoso diseño, proveniente de las matemáticas y extendido luego a la economía y el Derecho, que pretende analizar y explicar el comportamiento de los individuos y sus interrelaciones. De esta manera, la Teoría de los Juegos sirve como un sistema de pruebas para explicar y entender un determinado modelo en el cual interactúan personas frente a una determinada situación ante la cual se agrupan y establecen relaciones de poder. ${ }^{78}$

En todo juego existen individuos o personas que actúan como "jugadores", quienes a su vez realizan "acciones" sobre la base de la "información" que tienen de los otros "jugadores" o personas, desarrollando al efecto un conjunto de "estrategias" y "tácticas" que buscan un "beneficio" (algunos autores lo llaman "pago") que terminará como toda acción en un "resultado".

Explica Altavilla que

“...La teoría de [los] juegos parte de nociones básicas para describir las interacciones que se desenvuelven en el mundo real. Los dos conceptos primarios son los que denomina "juegos de puro conflicto", donde lo que una de las partes gana, la otra lo pierde y "juegos de pura coordinación", donde los jugadores pueden maximizar sus ganancias a través de estrategias concertadas. Sin embargo, resulta difícil encontrar en las interacciones del

provincias. Esa gestación institucional ubica a los tratados o leyes convenios celebrados entre las provincias y el gobierno nacional con un rango normativo específico dentro del derecho federal. Prueba de su categoría singular es que no es posible su derogación unilateral por cualquiera de las partes (Horacio Zorraquín Becú: El Federalismo Argentino, Edit. Perrot, 1958, p. 194)."

78 Sierralta Ríos, Anibal. (1998). "Breve introducción a la teoría de los juegos y su aplicación en el derecho". THEMIS: Revista de Derecho, № . 38, 1998 (Ejemplar dedicado a: Derecho Civil), pp. 277-288. 
mundo real estas dos constelaciones en forma pura. Desde un punto de vista empírico y metodológico, resultan más útiles los denominados juegos de motivación mixta [mixedmotive games] (o juegos de suma variable [variable-sum games]) en los que las preferencias de los jugadores están en parte en armonía y en parte en conflicto..." ${ }^{\prime 79}$

El juego que se aplica en este análisis es "La batalla de los sexos". En su versión tradicional el juego consiste en una pareja que deciden pasar un momento juntos, y uno de los integrantes (jugador 1) prefiere ir a ver un espectáculo (por ej. futbol) y el otro integrante de la pareja (jugador 2) prefiere ir a ver otro espectáculo (por ej. teatro), pero ambos prefieren compartir el espectáculo del otro antes que quedarse sólo. El esquema de estrategias y pagos (beneficios) sería el siguiente ${ }^{80}$ :

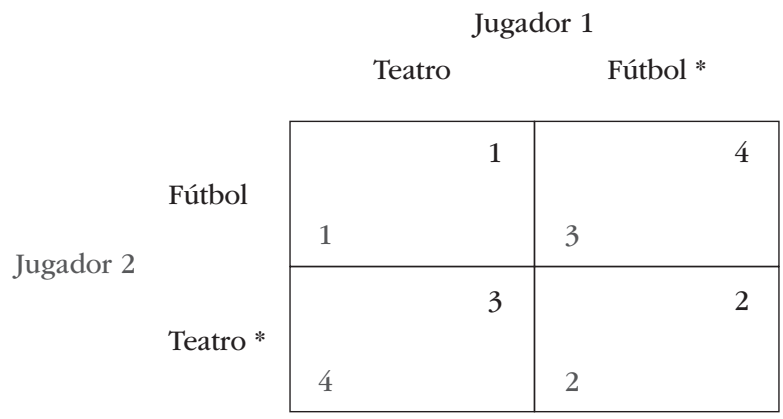

El * indica la opción preferida por cada jugador. En la parte superior derecha están los pagos (beneficios) del jugador 1 y en la parte inferior izquierda los correspondientes al jugador 2.

Explica Scharpf ${ }^{81}$ al discutir las implicaciones de estas constelaciones de motivaciones mixtas, las estrategias disponibles

\footnotetext{
79 Altavilla, Cristian (2012). "Procesos ...," ob . cit., p. 178.

80 El este caso el mejor equilibrio de Nash se encontraría en la opción J1 Fútbol, J2 Teatro, pero dicho resultado es subóptimo frente a la opción J1 Fútbol, J2 Fútbol mejor resultado para el Jugador 1 y, la opción J1 Teatro, J2 Teatro mejor resultado para el jugador 2.

81 Scharpf, Fritz W. (1997). “Games real actors play: actor-centered institutionalism in policy research". Oxford. Editorial WestviewPress, p. 73.
} 
para ambos jugadores son etiquetadas convencionalmente como 'cooperar' (C) y 'desertar' (D), dependiendo si la estrategia está destinada a alcanzar el interés común de las partes (cooperar) o a maximizar las ventajas de una parte a expensas de la otra (desertar). En otras palabras, la clasificación desertar es de tipo individualista.

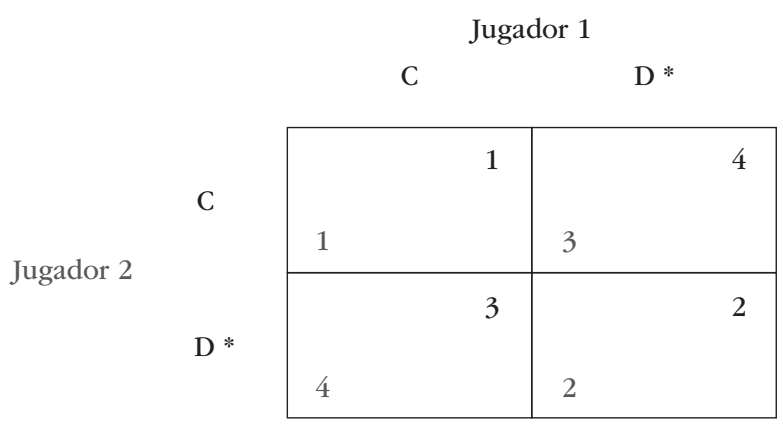

Si nos encontráramos frente a un juego no cooperativo ${ }^{82}$ en el que los jugadores deban realizar su movida (elegir la estrategia) en forma simultánea y sin comunicación previa, si ambos eligen "cooperar" se encontrarían en el peor resultado. Scharpf explica que las dificultades no desaparecerían si la comunicación e incluso los acuerdos vinculantes fueran posibles, porque ahora las partes estarían en desacuerdo sobre la elección entre los dos resultados coordinados que difieren en sus características distributivas. Por lo tanto, las negociaciones se asociarían con altos costos de transacción ${ }^{83}$.

Los costos de transacción se reducirían si se juega en forma secuencial, de esta forma el jugador que tiene el primer movimiento podría seleccionar su resultado preferido, y teniendo en cuenta ello, la mejor opción racional del otro sería coordinar el mismo resultado.

82 Los juegos no cooperativos tratan de situaciones donde las partes no pueden suscribir acuerdos obligatorios para todos.

83 Scharpf, Fritz W. (1997). "Games..." ob. cit, p. 74. 
En el ejemplo, si el jugador 1 elige la opción D que otorga pagos de 4 y 2 , la mejor elección para el jugador 2 sería la $\mathrm{C}$, ya que esta otorga un pago de 3 frente a la opción $\mathrm{D}$ que otorga un pago de 2 .

Como explica Altavilla siguiendo a Sharph ${ }^{84}$ los pagos se modifican, transformando las matrices, de acuerdo con las orientaciones que en la interacción adopten los actores. Existen cinco reglas de transformación el individualismo ${ }^{85}$, solidaridad $^{86}$, competición $^{87}$, altruismo $^{88}$ y hostilidad ${ }^{89}$.

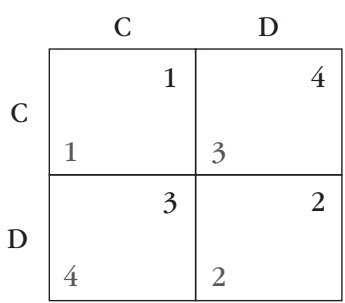

Individualista

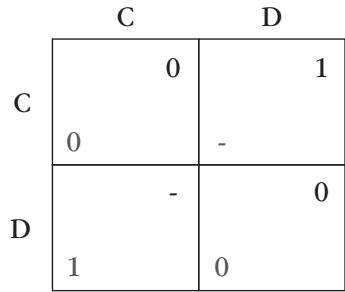

Competitivo

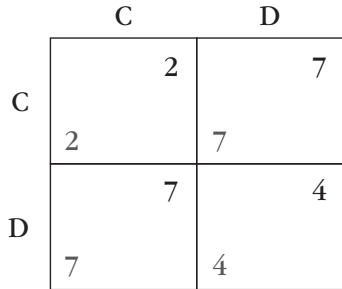

Solidario

Cada jugador puede adoptar orientaciones distintas. Altavilla en su análisis entiende que la Nación en el "Pacto Federal Fiscal I" adoptó una posición individualista y las provincias adoptaron una posición solidaria o cooperativa.

\footnotetext{
84 Si bien Altavilla transpone en su trabajo las matrices modificadas en la misma forma en que lo expone Scharpf en "Games..." Ob. cit, p. 88, dicha matriz debe ser reacomodada si en la misma se agrega de una posición de "cooperar" o "desertar". Partiendo que la matriz de pago individualista es igual a la matriz original en la que los jugadores sólo tienen en cuentas sus ganancias y pérdidas.

85 Sólo se consideran las ganancias/perdidas propias.

86 Cooperación si restricción. Las ganancias/perdidas propias y ajenas son igualmente evaluadas.

87 Las ganancias/perdidas propias y ajenas son evaluadas considerándose una perdida cuando la ganancia de la contraparte es mayor a la propia, y considerándose una ganancia cuando la perdida de la contraparte es mayor que la perdida propia.

88 Sólo se consideran las ganancias del otro. La ganancia de la contraparte se aprecia como propia.

89 Sólo se consideran las pérdidas del otro. La pérdida de la contraparte se aprecia como ganancia propia.
} 
En este punto no se coincide con el análisis, ni para el caso de 1992 ni para el caso actual. Entiendo que las orientaciones en la interacción tanto de las provincias como de la Nación es individualista, la Nación y las provincias buscan maximizar su resultado o en el peor de los casos minimizar las perdidas. Las motivaciones de uno y otro son distintas en tanto para las provincias prima el tema de recursos económicos y para la Nación prima la obtención de recursos políticos (votos en el congreso) por tanto resultan de interés los esquemas de pagos secundarios que se puedan acordar en uno u otro sentido para lograr un acuerdo.

La tensión institucional que provoca el federalismo en la distribución de recursos, y las reglas institucionales que regulan la coparticipación federal y las asignaciones específicas, tienden a orientar la actuación de las partes al aseguramiento de recursos para el cumplimiento de sus funciones. Por ello primará una visión individualista desde lo económico.

Por otra parte, cualquier modificación o afectaciones para fines determinados tal como lo pretende habitualmente la Nación, requiere de mayorías especiales no resultando suficiente para la Nación la firma del acuerdo por los gobernadores. En otras palabras, la Nación no puede imponer por si sola los términos, sino que requerirá del apoyo político de las provincias para alcanzar las mayorías especiales en el Congreso. Las provincias necesitan fondos para afrontar los costos de los servicios que brindan, los mismo se obtienen habitualmente por sistemas de pagos secundarios (obras en las provincias, fondo de soja, etc.) que dependen exclusivamente de la voluntad de la Nación. Así en caso de no lograr el acuerdo no obtendrían dichos pagos secundarios.

La necesidad de votos y de pagos secundarios, hace que una salida no negociada tenga un alto costo para ambas partes.

Por ello resulta adecuado la utilización de "La batalla de los sexos" para entender el proceso de negociación, puesto que para ambas partes siempre es mejor un mal acuerdo que la ausencia de acuerdo. 


\section{IV.4.2. ¿Quién gana y por qué?}

Estas negociaciones a primera vista parecen juegos de suma cero, en los cuales lo que una parte gana es igual a lo que la otra parte pierde, pero un análisis más profundo lleva a concluir que no se tratan de juegos de suma cero.

Para ejemplificarlo, en principio cuando una parte de un tributo va a la Nación es cierto que esa misma proporción no la obtienen las provincias, hasta ahí tenemos un juego no cooperativo de suma cero. Pero los acuerdos fiscales no incluyen sólo distribución de recursos sino también otros aspectos de tipo económico en el que el sacrificio de una parte no implica necesariamente una ganancia para la contraparte, o a la inversa en la que la ganancia de una parte no implicaría un perjuicio para la contraparte.

Esto se ve claro en el "Consenso Fiscal", las provincias acordaron una disminución de sus propios tributos, ello en modo alguno implica que esa pérdida de ingresos se convierta en ingresos de la Nación. El pagó para la Nación está dado por intentar cumplir la promesa electoral de "mejorar la competitividad" de los productos argentinos. También se aprecia que no se trata de un juego de suma cero cuando la compensación que recibe la Provincia de Buenos Aires no termina perjudicando en un primer momento a las provincias, sino que se financia con la eliminación de parte de las asignaciones específicas que tenía el sistema previsional.

Entonces en vez de establecer quién gana, la pregunta a hacerse es cuánto gana o pierde cada actor. Así en el "Consenso Fiscal” no sólo ganó la Nación al lograr la mayoría de los objetivos, sino que quién más ganó fue la Provincia de Buenos Aires, que en este caso tuvo una clara actuación de "free rider".

Al hablar de los hechos señalábamos que la prensa decía "La cuestión bonaerense, eco de unitarios y federales, estuvo

90 Los problemas de competitividad de argentina no están directamente vinculados a los tributos provinciales, sino a otras estructuras de costos. 
siempre presente porque se discutían sobre fondos para Buenos Aires pero el gobierno de Vidal no estaba sentado en la mesa. Frigerio-De Luca oficiaron de patrocinantes de la causa bonaerense" 91 .

El comportamiento oportunista que describe Altavilla en su hipótesis de trabajo está presente en el "Consenso Fiscal".

Por otra parte, se coincide con Altavilla en que el diseño institucional federal permite que los actores puedan adoptar comportamientos oportunistas y sacar ventajas en orden a los propios intereses que representan. Esto es un factor común en este tipo de negociaciones en las que hay, no sólo negociaciones entre las constelaciones de actores, sino que también hay negociaciones bilaterales o multilaterales. Ello puede verse plasmado en el texto del "Consenso Fiscal" cuando las actividades hidrocarburiferas quedan exceptuadas del esquema de alícuotas máximas (beneficiando ello exclusivamente a las provincias petroleras).

Los comportamientos oportunistas y de corto plazo, no limitados por el federalismo, hacen que al finalizar la negociación la situación de cada actor sea diferente.

Establecido que las ganancias o pérdidas no deben evaluarse en general para la constelación de actores, sino por cada actor, los esquemas de pagos para todas las provincias se ven alterados con relación a cada una teniendo en cuentas los pagos (beneficios) o pérdidas secundarias. Ello explica porque San Luís no firmó. San Luís tiene un juicio ganado por cobrar al cual debía renunciar a cambio de un compromiso eventual de pago, y admitía que Provincia de Buenos Aires sólo con una demanda empezara a cobrar lo que reclamaba. Sin lugar a duda las perdidas secundarias de San Luis no eran comparables a las pérdidas que pudieran tener otras provincias.

¿Por qué la Nación habitualmente consigue todo o gran parte de lo que se propone?. En este punto quien puede realizar

91 Ibáñez, Pablo. (16/11/2017). "Pacto...", ob. cit. 
la primera oferta o quien primero puede elegir y exponer sus preferencias tiene una ventaja sustancial, dado que siendo altos los costos ante la falta de acuerdo quien juega en segundo lugar tiene entre sus opciones perder mucho o perder poco. Pero nunca podrá lograr un mejor resultado que quien realizó la primera movida.

Es curioso como el ex ministro Frigerio tenía en claro este asunto y lo declaró frente a la prensa "hace 25 años que me dedico a temas de provincias: en todos los pactos fiscales, la Nación primereó a las provincias. Esta vez nosotros no queremos que pierdan dijo el ministro" ${ }^{22}$. Más allá de las declaraciones y las intenciones declamadas, utilizando los términos del ex Ministro, esta vez también la Nación primereó a las provincias.

Para las provincias el mejor resultado hubiera sido posponer la discusión para otro momento, lo cual permitía seguir con el esquema judicial y el esquema fiscal propio. Posponer también implicaba mantener en suspenso el Pacto Federal Fiscal II de 1993 y asumir el riesgo de un fallo desfavorable de la CSJN en el caso del fondo del conurbano. Pero recaído aún un eventual fallo desfavorable luego también se podría haber negociado.

Traduciendo lo sucedido al juego de la batalla de los sexos, la opción preferida para la Nación era el Consenso Fiscal propuesto (Consenso), y la opción preferida por las provincias era posponer la discusión (posponer). Seguiremos el esquema de pagos (beneficios) que se está utilizando ${ }^{93}$, y la secuencia de juego ocurrida para realizar el análisis.

\footnotetext{
92 Ibáñez, Pablo. (16/11/2017). "Pacto...", ob. cit.

93 Los números que se asignan a los pagos (beneficios) son arbitrarios dado que tienen que ver con una valoración asignada por los jugadores, es importante destacar que el esquema de pagos mantiene las proporciones según la orientación de los jugadores. En una orientación individualista el mejor resultado para los jugadores es un resultado coordinado en función a su preferencia (4 puntos), el segundo mejor resultado es un resultado coordinado en función de la preferencia de la contraparte (3 puntos), el tercer mejor resultado es un resultado no coordinado en función a su preferencia (2 puntos), y el peor resultado es aquel no coordinado en función de la preferencia de la contraparte (1 punto).
} 


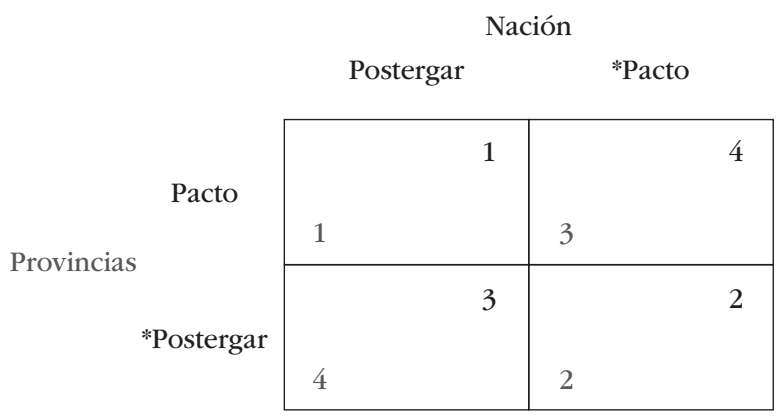

La primera movida la tiene la Nación quien selecciona la opción Pacto.

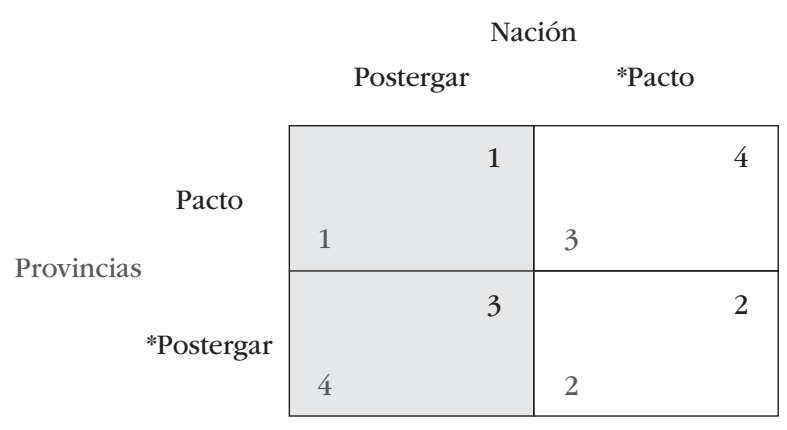

A las provincias les quedaba la opción de un resultado coordinado si optan por pacto (con un pago/beneficio de 3) o un resultado no coordinado si optan por postergar (con un pago/beneficio de 2). Lógicamente con un actuar racional se inclinaron por elegir Pacto, quedando el juego resuelto de la siguiente manera.

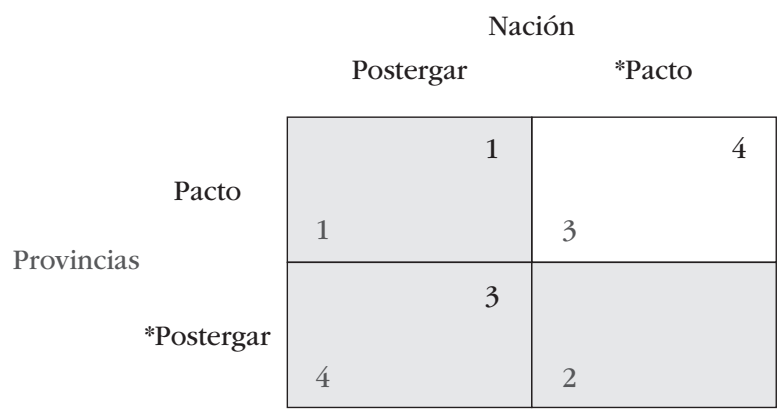


Hay un tema más que no es contemplado en la hipótesis de Altavilla y por tanto excede el objeto del presente, y ello es cómo se obliga a los actores a intervenir en el juego. Hemos visto la ventaja que tiene quien realiza la primera movida, pero existe un punto anterior, ante el cual corresponde preguntarse ¿por qué los jugadores aceptan participar del juego?, o también cabe preguntarse si ¿pueden los actores rechazar la participación?

\section{Conclusiones}

De lo expuesto surge como conclusión que el modelo de análisis que propone Altavilla para los procesos de negociación de pactos fiscales es apropiado para lograr entender el mismo.

La aplicación de la teoría de los juegos, en especial de "La batalla de los sexos" facilita el análisis del proceso de negociación y los motivos por los que se producen los resultados.

Se ha podido verificar que los actores se integran formando constelaciones, en las cuales, dependiendo de las circunstancias históricas, el factor común de unión puede variar. En algunos casos la unión es de tipo político, en otros la unión es por características de las provincias (chicas o grandes), actividades económicas relevantes en las provincias (por ej. el petróleo o la actividad vitivinícola), y en otras la unión está basada en la resistencia a la propuesta.

La Nación pudo realizar la primera movida (primereó) a las provincias. Los gobernadores trabajaron cada uno en tratar de obtener beneficios o evitar pérdidas para sus jurisdicciones, intentando aprovechar cada oportunidad.

Encontramos que, desde otra óptica y en otro momento histórico, se ha podido verificar la hipótesis en tanto ciertas características del diseño institucional posibilitan comportamientos oportunistas y de "free rider" en ambos niveles de gobierno. El contexto institucional en donde los actores se desenvuelven está definido por su debilidad (dado que no constriñe lo suficientemente los comportamientos oportunistas) y, consecuentemente, por su maleabilidad y flexibilidad por parte de los mismos 
actores involucrados en orden a sus propios intereses. Por lo tanto, el comportamiento oportunista y de corto plazo es parte del conjunto de reglas que rigen las relaciones entre los distintos niveles de gobierno.

\section{Bibliografía}

Altavilla, Cristian (2012). "Procesos de Negociación en las relaciones intergubernamentales. El Pacto Fiscal Federal I", Revista Perspectivas de Políticas Públicas, Argentina, Año $1 \mathrm{~N}^{\circ} 2$ (Enero-junio 2012), pp. 175 - 220.

Argento, Analia (13/12/2017). "El Ejecutivo advirtió que si no se aprueba la Reforma Previsional se caerá el pacto fiscal". Infobae recuperado el 17 de diciembre de 2017 de https://www. infobae.com/politica/ 2017/12/13/el-ejecutivo-advirtio-que-sino-se-aprueba-la-reforma-previsional-se-caera-el-pacto-fiscal/

Argento, Analia (18/12/2017). "El silencio de los gobernadores que dieron quórum y la foto que necesitaba el Gobierno". Infobae recuperado el 12 de enero de 2018 de https://www.infobae.com/politica/2017/12/18/el-silencio-de-los-gobernadoresque-dieron-quorum-y-la-foto-que-necesitaba-el-gobierno/.

Braslavsky, Guido (29/11/2017). "El Senado dio media sanción a la reforma previsional y al Pacto fiscal con las provincias". Clarín recuperado el 16 de diciembre de 2017 de https://www.clarin.com/politica/senado-avanzo-aprobacion-leycambia-movilidad-jubilatoria_0_HJDxFkTgM.html

Bravo, Martín (06/11/2017). "En medio de la tensión por el reclamo del Fondo del Conurbano, Ricardo Lorenzetti recibió a María Eugenia Vidal". Clarín, recuperado el 16 de diciembre de 2017 de https://www.clarin.com/politica/medio-tension-reclamofondo-conurbano-ricardo-lorenzetti-recibio-maria-eugeniavidal_0_S1GwIIARZ.html

Bravo, Martín (14/11/2017). "Pacto fiscal: el Gobierno le mete presión a las provincias, pero ya analiza alternativas para el acuerdo". Clarín, recuperado el 16 de diciembre de 2017 de https://www.clarin.com/politica/gobierno-presiona-evaluaalternativas_0_H11ap1YJf.html 
Bullrich, LuCReCia (08/11/2017). "Malestar en las provincias por la foto de Vidal con Lorenzetti". La Nación, recuperado el 16 de diciembre de 2017 de http://www.lanacion.com.ar/2080265malestar-en-las-provincias-por-la-foto-de-vidal-con-lorenzetti.

Bullrich, Lucrecia (09/11/2017). "El pacto fiscal de 1993 acecha a los mandatarios". La Nación, recuperado el 17 de diciembre de 2017 de "http://www.lanacion.com.ar/2080597-el-pacto-fiscalde-1993-acecha-a-los-mandatarios

Bullrich, Lucrecia (12/11/2017). "Los gobernadores dudan de que se pueda firmar el pacto fiscal esta semana". La Nación, recuperado el 16 de diciembre de 2017 de http://www.lanacion. com.ar/2081633-los-gobernadores-dudan-de-que-se-puedafirmar-el-pacto-fiscal-esta-semana.

BullRICH, LuCRECIA (16/11/2017). "El Gobierno intenta destrabar el acuerdo con las provincias". La Nación, recuperado el 16 de diciembre de 2017 de http://www.lanacion.com.ar/2082751el-gobierno-intenta-destrabar-el-acuerdo-con-las-provincias.

Clarín (18/12/2017). "Reforma previsional: 12 gobernadores se mostraron juntos para apoyar el proyecto", recuperado el 12 de enero de 2018 de https://www.clarin.com/politica/ reforma-previsional-12-gobernadores-mostraron-juntos-apoyar-proyecto_0_BkqaBOBGM.html.

Comisión Federal de Impuestos. Resolución General Interpretativa 35/2014, recuperada el 4 de enero de 2018 de http://www. cfi.gov.ar/docs/resoluciones/rgi/r_g_i_n_35_2014.pdf, y Resolución General Interpretativa 36/2017 recuperada el 4 de enero de 2018 de http://www.cfi.gov.ar/docs/resoluciones/ reservadas/ r_g_i_n_36_2017.pdf .

CSJN (1999). "Asociación de Grandes Usuarios de Energía Eléctrica de la República Argentina (AGUEERA) c/ Buenos Aires, Provincia de y otro s/ acción declarativa" en sentencia de fecha 19 de agosto de 1999

Dalto, Veronica (02/10/2017). "El Gobierno se queda con la carta del Pacto Fiscal para negociar en 2018 con provincias”. El Cronista, recuperado el 16 de diciembre de 2017 de https:// www.cronista.com/economiapolitica/El-Gobierno-se-quedacon-la-carta-del-Pacto-Fiscal-para-negociar-en-2018-con-provincias-20171002-0038.html 
Diario Ámbito Financiero (15/11/2017). "Pacto fiscal: Frigerio se reunió con gobernadores y aseguró que están "más cerca de un acuerdo", recuperado el 16 de diciembre de 2017 de http:// www.ambito.com/903560-pacto-fiscal-frigerio-se-reunio-congobernadores-y-aseguro-que-estan-mas-cerca-de-un-acuerdo

Diario Ámbito Financiero (14/12/2017). "Carrió advierte que una reforma previsional por DNU "violaría gravemente la Constitución", recuperado el 16 de diciembre de 2017 de http:// www.ambito.com/906628-carrio-advierte-que-una-reformaprevisional-por-dnu-violaria-gravemente-la-constitucion.

Diario Ámbito Financiero (18/12/2017). "Antes de la sesión, Frigerio y Peña armaron foto de apoyo de gobernadores a la reforma", recuperado el 12 de enero de 2018 de http://www.ambito. com/906858-antes-de-la-sesion-frigerio-y-pena-armaron-fotode-apoyo-de-gobernadores-a-la-reforma.

DifusionInfo (30/10/2017). "Histórico discurso del Presidente Macri en el CCK | 30-10-2017" [video]. Consultado el 17 de diciembre de 2017 de https://youtu.be/Eb6H3i6_2iQ.

El Diario de la República (30/11/2017). "Alberto: "No pasará nada por no firmar, las obras continuarán”, recuperado el 17 de diciembre de 2017 de https://www.eldiariodelarepublica.com/ nota/2017-11-30-20-56-26-alberto-rodriguez-saa-el-consensofiscal-solo-beneficia-a-la-nacion-y-a-buenos-aires.

El Litoral (27/01/2018). "Nación retiene fondos a provincias que aún no avalaron el Pacto Fiscal, entre ellas Corrientes", recuperado el 5 de febrero de 2018 de http://www.ellitoral.com. ar/nota/2018-1-27-4-0-0-nacion-retiene-fondos-a-provinciasque-aun-no-avalaron-el-pacto-fiscal-entre-ellas-corrientes .

Honorable Cámara de Diputados de la Nación (2017). "SESIÓn COMPLETA 2da PARTE: H. Cámara de Diputados de la Nación - 21 de Diciembre de 2017" [video]. Publicado el 26 diciembre de 2017, consultado el 22 de enero de 2017 de https:/youtu.be/ IJRoSjQYppk?t=10366

IbaÑez, Pablo (07/11/2017). "Alerta entre los gobernadores por la foto María Eugenia Vidal-Ricardo Lorenzetti". Clarín, recuperado el 16 de diciembre de 2017. https://www.clarin.com/ politica/alerta-gobernadores-foto-maria-eugenia-vidal-ricardolorenzetti_0_S15ss5JkM.html. 
IвáÑez, Pablo (09/11/2017). "Los detalles del Pacto Fiscal que el Gobierno negocia con las provincias". Clarín, recuperado el 17 de diciembre de 2017 de https://www.clarin.com/politica/inquietud-provincias-preparan-discutir-letra-chica_0_BkXI1rMkf.html.

IвÁÑEZ, PABLo (16/11/2017). "Pacto fiscal: negocian esta mañana en la Rosada para cerrar el acuerdo y firmar con Mauricio Macri". Clarín, recuperado el 16 de diciembre de 2017 de https://www. clarin.com/politica/pacto-fiscal_0_B1wMGH5yz.html

INDEC. "Censo del año 2010", información consultada en https:// www.indec.gov.ar/censos_total_pais.asp? id_tema_1=2\&id_ tema_2=41\&id_tema_3 $=135 \& \mathrm{t}=3 \& \mathrm{~s}=0 \& \mathrm{c}=2010$

IProfesional (06/11/2017). "Vidal se reunió con Lorenzetti y dijo que el reclamo por el Fondo del Conurbano 'es justo y legítimo'.", recuperado el 16 de diciembre de 2017 de http://www. iprofesional.com/notas/258400-lorenzetti-corte-suprema-tipode-cambio-vidal-tarifa-tribunal-fiscal-de-la-nacion-tribunalesVidal-se-reunio-con-Lorenzetti-y-dijo-que-el-reclamo-por-elFondo-del-Conurbano-es-justo-y-legitimo?page_y=0

Jueguen, Francisco (18/08/2017). "El Gobierno pacta con los gobernadores contener el gasto y el empleo público”. La Nación, recuperado el 16 de diciembre de 2017 de https://www.lanacion.com.ar/2054405-el-gobierno-pacta-con-los-gobernadorescontener-el-gasto-y-el-empleo-publico.

La GaCeTA de SALTA (07/11/2017). "Lorenzetti recibió a Vidal, en medio de la tensión por el reclamo del Fondo del Conurbano", recuperado el 16 de diciembre de 2017 de https://www.lagacetasalta.com.ar/ nota/93040/actualidad/lorenzetti-recibio-vidalmedio-tension-reclamo-fondo-conurbano.html

La NaCión (30/10/2018) "Mauricio Macri, en el CCK: "Tenemos que avanzar en reformas donde cada uno ceda un poco", recuperado el 16 de diciembre de 2017 de http://www.lanacion.com. ar/2077597-mauricio-macri-plan-de-reformas-cck.

La NACión (18/12/2017). "El quorum, la clave de la sesión por la reforma previsional: el cálculo oficial y la desconfianza del FPV" recuperado del 12 de enero de 2018 de http://www. lanacion.com.ar/2092463-la-batalla-por-el-quorum-la-clavede-la-sesion-por-la-reforma-previsional-el-calculo-oficial-yla-desconfianza-del-fpv. 
LANDERA, Federico (2017). "Elecciones 2017 vs. 2015: el nuevo mapa político del país". Universidad Austral. Se ha consultado una presentación recuperada el 10 de enero de 2018 de https:// www.slideshare.net/jucarguello/elecciones-2017-vs-2015-elnuevo-mapa-poltico-del-pas?from_action=save. Véase también presentación oficial de la Universidad en http://www.austral. edu.ar/contenido/2017/10/elecciones-2017-vs-2015-elnuevo-mapa-politico-del-pais/

Leiras, Marcelo (2013). "Las contradicciones aparentes del federalismo argentino y sus consecuencias políticas y sociales". En AcuÑa, Carlos H. (compilador). ¿Cuánto importan las Instituciones?. Buenos Aires. Ed. Siglo XXI Editores, ps 209-245. La cita es de p. 229.

LMNeuquen.com (18/12/2017). "Trece gobernadores manifestaron su apoyo a la reforma previsional" recuperado el 12 de enero de 2018 de https://www.lmneuquen.com/trece-gobernadoresmanifestaron-su-apoyo-la-reforma-previsional-n 574850 .

Mercado, Silvia (09/11/2017). "Todo listo para la firma de los primeros acuerdos entre Mauricio Macri y los gobernadores". Infobae, recuperado el 17 de diciembre de 2017 de https:// www.infobae.com/politica/2017/11/09/todo-listo-para-lafirma-de-los-primeros-acuerdos-entre-mauricio-macri-y-losgobernadores/

Pertot, Werner (13/11/2017). "Zanahoria y garrote para las provincias”. Página 12, recuperado el 16 de diciembre de 2017 de https://www.pagina12.com.ar/75591-zanahoria-y-garrotepara-las-provincias.

Poder Ejecutivo Nacional. Decreto 19/94 recuperado el 4 de enero de 2018 de http://www.cfi.gov.ar/docs/ PactoII.pdf

Poder Ejecutivo Nacional. Decreto 2635/2015, recuperado el 14 de diciembre de 2017 de http://servicios.infoleg.gob.ar/infolegInternet/anexos/255000-259999/255838/norma.htm.

Poder Ejecutivo Nacional. Decreto 73/2016, recuperado el 14 de diciembre de 2017 de http://servicios.infoleg.gob.ar/infolegInternet/anexos/255000-259999/257722/norma.htm.

SCHARPF, FriTz W. (1997). "Games real actors play: actor-centered institutionalism in policy research". Oxford. Editorial WestviewPress. 
Sierralta Ríos, Anibal (1998). "Breve introducción a la teoría de los juegos y su aplicación en el derecho". THEMIS: Revista de Derecho, $\mathrm{N}^{\circ}$. 38, 1998 (Ejemplar dedicado a: Derecho Civil), pp. $277-288$.

TеLam (16/11/2017). "Frigerio define el alcance del pacto fiscal con los gobernadores" recuperado el 17 de diciembre de 2017 de http://www.telam.com.ar/notas/201711/223278-gobernadores-mauricio-macri-pacto-fiscal-rogelio-frigerio.html

Telam (22/11/2017). "En San Luis se quejan de un 'apriete' de la Nación y de otras provincias" recuperado el 17 de diciembre de 2017 de http://www.telam.com.ar/notas/201711/225282-ensan-luis-se-quejan-de-un-apriete-de-nacion-y-otras-provinciaspor-el-pacto-fiscal.html

Telam (25/01/2018) "Dura advertencia de Dujovne a los gobernadores que no cumplan el pacto fiscal". La Voz, recuperado el 5 de febrero de 2018 de http://www.lavoz.com.ar/politica/duraadvertencia-de-dujovne-los-gobernadores-que-no-cumplan-elpacto-fiscal

TORINO, MarTín (10/11/2017). "El Gobierno prevé cerrar el acuerdo el próximo jueves, pero con disensos". El Cronista, recuperado el 16 de diciembre de 2017 de https://www.cronista.com/ economiapolitica/El-Gobierno-preve-cerrar-el-acuerdo-el-proximo-jueves-pero-con-disensos-20171110-0056.html.

Zurbriggen, Cristina (2006). "El institucionalismo centrado en los actores: una perspectiva analítica en el estudio de las políticas públicas". Revista de Ciencia Política, Santiago de Chile, Volumen 26, $\mathrm{N}^{\mathrm{o}} 1$ (2006), pp. 67-83, recuperado el 18 de enero de 2018 de https://dx.doi.org/10.4067/S0718090X2006000100004. 